INRA, Prod. Anim. 2005, 18 (1), 49-62

\title{
Facteurs de production et qualité sensorielle des fromages ${ }^{1}$
}

\author{
J.B. COULON ${ }^{1}$, A. DELACROIX-BUCHET ${ }^{2}$, B. MARTIN ${ }^{1}$, A. PIRISI ${ }^{3}$ \\ ${ }^{1}$ INRA, Unité de Recherches sur les Herbivores, F-63122 Theix \\ 2 INRA, Unité de Recherches Laitières et Génétique Appliquée, F-78352 Jouy-en-Josas \\ ${ }^{3}$ Istituto Zootecnico e Caseario per la Sardegna, I-07040 Olmedo \\ Courriel : jbc@clermont.inra.fr
}

Les caractéristiques sensorielles des fromages sont une préoccupation importante des filières. Leur liaison avec les facteurs de production du lait sont à l'origine de nombreux débats, en particulier dans le cadre de l'élaboration de cahiers des charges spécifiques. Ces caractéristiques sensorielles dépendent-elles de la race des animaux, de leur état sanitaire ou de leur alimentation ? Ce texte fait la synthèse des travaux réalisés sur le sujet depuis une dizaine d'années et propose quelques éléments d'explication des effets mis en évidence.

La qualité sensorielle des fromages dépend d'un grand nombre de facteurs, liés à la fois à la technologie de fabrication et aux caractéristiques chimiques et microbiologiques de la matière première mise en œuvre. Ces dernières dépendent elles-mêmes de nombreux facteurs d'amont (d'origine génétique, physiologique, alimentaire...). Ces facteurs d'amont sont de plus en plus au centre des préoccupations des consommateurs qui s'interrogent en particulier sur l'alimentation offerte aux animaux. Ils revêtent une importance toute particulière dans le cas des produits marqués (Appellation d'Origine Contrôlée, Indication Géographique Protégée, labels...) pour lesquels les modifications de la matière première au moment de la transformation sont limitées voire interdites et qui revendiquent un lien fort avec les conditions de production du lait, dont certaines sont à la base de la notion de terroir (Grappin et Coulon 1996). Les relations entre ces conditions de production (alimentation et type d'animal en particulier) et les caractéristiques des fromages sont souvent mises en avant par les fromagers, sur la base d'observations empiriques. Jusqu'à récemment, il n'existait cependant que peu de travaux expérimentaux sur le sujet, en raison, entre autres, de la difficulté de séparer correctement les effets propres de ces facteurs d'amont de ceux qui sont liés à la transformation fromagère proprement dite. Depuis quelques années, plusieurs études spécifiques ont été mises en œuvre pour préciser ces liaisons. Elles ont été per- mises par le développement des méthodes d'analyses des caractéristiques sensorielles des fromages et par la maîtrise ou le contrôle des paramètres technologiques de fabrication fromagère. Elles concernent à la fois des travaux réalisés en conditions expérimentales sur les laits de mélange de quelques animaux et des approches plus globales, réalisées chez des producteurs fermiers ou des transformateurs industriels. Dans tous les cas, les facteurs de variation liés aux caractéristiques et à la conduite des animaux étaient contrôlés et la technologie fromagère était semblable entre les traitements : dans la majorité des cas, les fromages étaient fabriqués dans des unités expérimentales et affinés dans un même lieu permettant une maîtrise et un contrôle optimal des différents paramètres de fabrication.

Après avoir présenté l'effet des facteurs génétiques, physiologiques et alimentaires sur les caractéristiques sensorielles des fromages, nous donnerons quelques hypothèses d'explication de ces effets.

\section{1 / Effet des caractéris- tiques génétiques}

De nombreuses études ont été réalisées pour évaluer l'effet des caractéristiques génétiques des animaux (race, polymorphisme des lactoprotéines) sur l'aptitude à la transformation fromagère du lait (aptitude à la coagulation, rendements fromagers) (tableau 1). On sait ainsi que les vaches de race Normande, Montbéliarde ou Brune produisent un lait plus riche en protéines et de meilleure aptitude fromagère que celui de vaches Holstein conduites dans les mêmes conditions (Froc et al 1988, Macheboeuf et al 1993, Malossini et al 1996, Auldist et al 2002, Mistry et al 2002) : le gel obtenu après adjonction de présure est plus ferme et les rendements fromagers plus élevés. L'essentiel de cet effet est lié d'une part aux différences de teneurs en caséines des laits d'une race à l'autre et d'autre part aux variations du polymorphisme génétique des lactoprotéines et en particulier à la fréquence du variant $B$ de la caséine $\kappa$. En effet, il est maintenant bien établi que les variants de cette caséine, dont la fréquence diffère fortement d'une race à l'autre, influencent l'aptitude à la coagulation des laits (Grosclaude 1988, Macheboeuf et al 1993). En fait, lorsque l'on tient compte de la teneur en caséines et des variants génétiques des lactoprotéines, les différences entre races disparaissent pratiquement totalement (Macheboeuf et al 1993, Auldist et al 2002). Par contre beaucoup moins de travaux ont été entrepris pour étudier les effets de ces facteurs génétiques sur les caractéristiques sensorielles des fromages.

1.1 / Effet de la race des différentes espèces laitières : vache, chèvre, brebis

Les quelques travaux entrepris sur l’effet de la race sur les caractéristiques sensorielles des fromages résultent

${ }^{1}$ Ce texte est la version française remaniée et mise à jour de la synthèse parue dans la revue Lait en 2002 (Coulon et al 2002). 
Tableau 1. Effet de la race sur l'aptitude à la coagulation du lait.

\begin{tabular}{|c|c|c|c|c|c|c|c|c|c|c|}
\hline Essai $^{1}$ & \multicolumn{3}{|c|}{1} & \multicolumn{3}{|c|}{2} & \multicolumn{2}{|c|}{3} & \multicolumn{2}{|c|}{4} \\
\hline Race $^{2}$ & $\mathrm{HO}$ & MO & TA & $\mathrm{HO}$ & MO & NO & $\mathrm{HO}$ & BS & $\mathrm{HO}$ & BS \\
\hline Nombre de vaches & 41 & 42 & 38 & 10 & 10 & 10 & 12 & 14 & 6 & 6 \\
\hline $\begin{array}{l}\text { Fréquence allélique du variant } B \\
\text { de la } \kappa \text { caséine }(\%)\end{array}$ & 27 & 46 & 26 & 25 & 55 & 75 & - & - & - & \\
\hline Taux butyreux (g/kg) & 35,3 & 34,6 & 33,5 & 36,3 & 35,3 & 38,1 & 34,8 & 36,5 & 40,6 & 41,5 \\
\hline Taux protéique $(\mathrm{g} / \mathrm{kg})$ & $29,3 a$ & $31,4 b$ & $30,7 b$ & $31,2 a$ & $32,9 a b$ & $34,9 b$ & $28,8 a$ & $31,0 b$ & $30,1 a$ & $33,6 b$ \\
\hline Caséines/protéines (\%) & 80,9 & 80,9 & 80,4 & 78,3 & 79,7 & 79,4 & $75,4 a$ & $78,9 b$ & - & - \\
\hline Calcium $(\mathrm{g} / \mathrm{kg})$ & $1,14 a$ & $1,19 b$ & $1,22 b$ & - & - & - & 1,08 & 1,20 & - & - \\
\hline Temps de coagulation $(\mathrm{min})^{3}$ & $9,1 a$ & $8,0 \mathrm{~b}$ & $7,6 \mathrm{~b}$ & $16,2 a$ & $14,9 a b$ & $13,2 b$ & 17,8 & 16,8 & $19,5 \mathrm{a}$ & $17,6 b$ \\
\hline Fermeté du gel $(\mathrm{mm})^{3}$ & $38,6 a$ & $47,8 \mathrm{~b}$ & $44,1 \mathrm{~b}$ & $38 a$ & $45 b$ & $48 b$ & $17 a$ & $26 b$ & $34,6 a$ & $39,5 b$ \\
\hline Taille des micelles $(\mathrm{nm})$ & - & - & - & $159 a$ & $138 b$ & $151 \mathrm{a}$ & - & - & - & - \\
\hline Rendement fromager ${ }^{4}$ & - & - & - & - & - & - & - & - & $10,2 a$ & $11,0 b$ \\
\hline
\end{tabular}

11 : Macheboeuf et al $1993 ; 2$ : Auldist 2 et al $2002 ; 3$ : Malossini et al $1996 ; 4$ : Mistry et al 2002.

${ }^{2} \mathrm{HO}$ : Holstein ; MO : Montbéliarde ; TA : Tarentaise ; NO : Normande ; BS : Brown Swiss.

3 à $\mathrm{pH}$ ajusté à 6,60 .

$4 \mathrm{~kg} / 100 \mathrm{~kg}$ lait.

Intra essai, les valeurs avec des lettres différentes sont significativement différentes $(P<0,05)$.

généralement d'interrogations des filières de fromages d'AOC concernant l'opportunité de restreindre, dans leur cahier des charges, la production de lait à certaines races et en particulier à celles traditionnellement exploitées dans la zone de production. Les premiers travaux entrepris en Auvergne n'avaient pas permis de mettre en évidence de très grandes différences sensorielles entre des fromages de Saint-Nectaire fabriqués avec du lait de vaches PieNoires ou Montbéliardes (Garel et Coulon 1990), hormis sur la couleur, plus jaune avec le lait de vaches PieNoires, mais les descripteurs sensoriels étaient dans cette étude peu nombreux. Plus récemment, les laits de vaches Tarentaises, Holstein et Montbéliardes ont été transformés en fromage de Saint-Nectaire, en conditions technologiques contrôlées et identiques d'une fabrication à l'autre, au cours de trois séries d'essais (tableau 2) dans lesquels on faisait également varier l'alimentation des vaches. Dans le premier essai, les fabrications ont eu lieu à partir du lait entier (Martin et al 2000). Dans les deux autres, le lait était standardisé par écrémage partiel avant fabrication (Verdier et al 1995, Verdier-Metz et al 1998). Dans le premier essai, des différences très importantes de texture ont été observées : les fromages issus de vaches Holstein ont été moins fermes et plus fondants que ceux issus de vaches Montbéliardes en raison d'un gras/sec plus élevé, lié à un rapport taux butyreux/taux protéique supérieur chez les Holstein. Ces différences ne se retrouvent pas dans les deux autres essais où le rapport taux butyreux/taux protéique était standardisé avant fabrication. $\mathrm{Au}$ contraire, dans ce cas, et quelle que soit la nature de la ration, les fromages fabriqués avec le lait de vache Holstein étaient plus fermes, moins fondants, plus granuleux que les fromages fabriqués avec le lait des vaches de races Tarentaise ou Monbéliarde. Ils ont aussi présenté un goût moins prononcé. Dans les 3 essais, les fromages issus du lait de vaches Holstein ont été plus jaunes que les autres. Dans le deuxième essai, les fromages issus du lait de vaches de races Montbéliarde et Tarentaise ont été globalement plus appréciés que ceux issus du lait de vaches de race Holstein.

En Normandie, une étude réalisée en site industriel a permis la comparaison de 18 fabrications de Pont-l'Evêque avec 3 répétitions sur des lots de laits de vaches Normandes ou Prim'Holstein ou de mélange à deux périodes de l'année (juin et septembre). Les meilleurs rendements fromagers sont obtenus avec les laits de race
Normande. Les Pont-l'Evêque issus du lait de vaches Holstein ont été plus fondants, moins élastiques et plus collants en bouche et ont présenté une odeur de levure plus marquée. Les fromages issus de lait de vaches Normandes ont été plus denses. Ils ont développé plus d'intensité et de complexité aromatiques au niveau de l'odeur comme du goût. Ils ont été marqués par un caractère plus fumé et plus aromatique (Ducy 1997). Ces résultats ont été en partie confirmés dans le cadre d'une étude récente réalisée en conditions expérimentales (Hurtaud et al 2004), où des fromages Camembert et Pont-l'Evêque ont été fabriqués à partir de lait issus de groupes de vaches de race Prim'Holstein et Normande. Dans cet essai, les fromages Pontl'Evêque ont été légèrement moins fermes lorsqu'ils étaient issus du lait de vaches Holstein. Des différences plus marquées ont été observées sur le

Tableau 2. Effet de la race de vache sur les caractéristiques sensorielles des fromages (Martin et al 2000, Verdier et al 1995, Verdier-Metz et al 1998).

\begin{tabular}{|l|c|c|c|c|c|c|}
\hline \multirow{2}{*}{} & \multicolumn{2}{|c|}{ Essai 1 } & \multicolumn{2}{c|}{ Essai 2 } & \multicolumn{2}{c|}{ Essai 3 } \\
\cline { 2 - 7 } & $\mathrm{HO}$ & $\mathrm{MO}$ & $\mathrm{HO}$ & $\mathrm{MO}$ & $\mathrm{HO}$ & $\mathrm{MO}$ \\
\hline Lait & & & & & & \\
Taux butyreux (g/kg) & $37,0^{* *}$ & 34,0 & 35,7 & 35,9 & 35,8 & 35,9 \\
Taux protéique (g/kg) & $29,4^{* *}$ & 31,7 & 34,0 & 33,9 & 33,4 & 33,7 \\
\hline Fromage & & & & & & \\
Extrait sec (\%) & $52,6^{*}$ & 51,8 & 55,3 & 55,0 & 54,6 & 54,7 \\
Gras/sec & $53,8^{* *}$ & 50,9 & 51,7 & 51,6 & 52,7 & 52,9 \\
Indice de jaune & $28,9^{* *}$ & 27,3 & 21,7 & 21,4 & $31,4^{*}$ & 30,4 \\
Texture ferme & $3,0^{* *}$ & 3,6 & 5,1 & 4,9 & $5,2^{* *}$ & 4,0 \\
Texture fondante & $5,2^{* *}$ & 4,5 & $3,2^{*}$ & 3,7 & $3,0^{* *}$ & 4,3 \\
Intensité du goût & 5,0 & 5,0 & 5,0 & 5,0 & $5,1^{* *}$ & 5,6 \\
Intensité de l'odeur & 4,5 & 4,8 & 4,2 & 4,1 & 5,2 & 5,3 \\
\hline
\end{tabular}

$\mathrm{HO}$ : Holstein ; $\mathrm{MO}$ : Montbéliarde.

${ }^{*}: P<0,05 ;{ }^{* \star}:<0,01$. 
Camembert, dont le goût a été globalement plus apprécié lorsqu'il était fabriqué avec du lait de vaches Normandes, mais uniquement lorsqu'elles recevaient un régime à base d'ensilage d'herbe.

Dans l'espèce caprine, les Norvégiens ont montré les premiers que la flaveur « chèvre » appréciée et recherchée dans les fromages produits dans le nord de l'Europe était un caractère héréditaire des populations de chèvres (Ronningen 1965, Bakke et al 1977) et que cette flaveur caractéristique dépendait aussi de la race des animaux. Plusieurs études mettent en effet en évidence que les fromages produits avec des laits de race Norvégienne comparés à ceux de race Saanen possédent une flaveur " chèvre " plus intense (Anonymous 1976, Bakke et al 1976, Skjevdal 1979, Bakkene 1985).

Dans l'espèce ovine, il n'y a, à notre connaissance, pratiquement pas de travaux concernant l'influence de la race sur les caractéristiques sensorielles du fromage. Gonzalez Viñas et al (1999) ont étudié les caractéristiques physico-chimiques et sensorielles de certains fromages à pâte dure produits dans différentes régions d'Espagne avec du lait de différentes races de brebis. Il n'y a pas eu de différences significatives dans la composition chimique des fromages en fonction de la race ou de la région. Les caractéristiques sensorielles des fromages ont été liées à leur composition chimique, mais pas à la race des animaux. Les propriétés rhéologiques de huit fromages de brebis AOC européens ont été étudiées par Pirisi et al (2000a). Les fromages considérés n'avaient généralement pas été élaborés avec la même technologie de fabrication et leur durée d'affinage était différente. On peut cependant considérer que les fromages Fiore Sardo (lait de brebis de race Sarde) et Idiazabal (lait de brebis Lacha) étaient comparables sur le plan de la technologie mise en œuvre et pour le temps d'affinage, de même que les fromages Pecorino Sardo (brebis Sarde) et Ossau-Iraty des Pyrénées (brebis Manech). L'étude a montré que les deux fromages sardes présentaient des caractéristiques rhéologiques voisines (pâte ferme et friable) même si la technologie de fabrication était distincte, et très différentes de celles de l'Ossau-Iraty dont la pâte présentait une forte cohésion. Dans cette étude, il semble donc que des différences de texture puissent être attribuées à la race des animaux.

\section{2 / Effet des variants géné- tiques}

L'effet bénéfique du variant $B$ des caséines $\kappa$ et $\beta$ sur les propriétés rhéologiques des laits coagulés et sur les rendements fromagers a été démontré dans de nombreuses études (Grosclaude 1988, Delacroix-Buchet et al 1993, Macheboeuf et al 1993). Le variant B confére un temps de caillage et un temps de raffermissement du caillé plus courts et conduit à un caillé plus ferme que le variant $\mathrm{A}$. Ces propriétés se traduisent par une plus grande facilité de transformation fromagère des laits possédant le variant $B$, accompagnée d'une meilleure rétention de la matière grasse dans le réseau de caséine d'où un meilleur rendement fromager pour un même taux de matière utile (protéines et matières grasses) des laits mis en fabrication. On peut par contre s'interroger sur les effets de ces variants sur les caractéristiques sensorielles du fromage affiné. La comparaison des trois «haplotypes » les plus fréquents des caséines $\alpha_{\mathrm{s} 1}, \beta$ et $\kappa\left(\mathrm{BBB}, \mathrm{BA}^{2} \mathrm{~A}\right.$ et $\mathrm{CA}^{2} \mathrm{~B}$ ) en race Normande (Grosclaude 1988) a permis de relativiser l'intérêt porté aux variants $B$ des caséines $\beta$ et $\kappa$ pour la transformation fromagère. En microfabrications expérimentales de fromages à pâte pressée (type SaintPaulin) avec des laits individuels sélectionnés sur la base du génotype, de la filiation et du stade de lactation comme de la composition chimique (rapports matières grasses/protéines identiques), l'association des variants B des caséines $\kappa$ et $\beta$ conduit à une augmentation de rendement fromager plus forte que celle obtenue avec chaque variant pris séparément. La microstructure du caillé BBB est plus serrée que celle des caillés $\mathrm{BA}^{2} \mathrm{~A}$ et $\mathrm{CA}^{2} \mathrm{~B}$, et la protéolyse primaire des fromages $\mathrm{BBB}$ est plus prononcée. En fin d'affinage, les fromages BBB sont plus fermes, moins élastiques et plus friables que les autres (NuytsPetit 1991, Nuyts-Petit et al 1997). Dans une autre étude, quarante-deux vaches laitières de race Holstein, Montbéliarde et Tarentaise ont été réparties en deux groupes sur la base des variants génétiques des caséines $\beta$ et $\kappa$. L'effet bénéfique des variants B sur les propriétés rhéologiques des laits a une nouvelle fois été confirmé mais il ne s'est pas accompagné de répercussion sur les caractéristiques physico-chimiques et sensorielles de fromages de SaintNectaire fabriqués avec les laits correspondants (Verdier-Metz et al 2000b).

Certaines races bovines comme la race Tarentaise inscrite dans le décret d'Appellation de l'AOC Beaufort, se distinguent des autres races laitières par une fréquence élevée de variants rares des caséines $\alpha_{\mathrm{s} 2}, \beta$ et $\kappa$. Ainsi, le variant $C$ de la caséine $\beta$ dont la fréquence atteint $17 \%$ en race Tarentaise est quasi absent dans la plupart des autres races de vaches laitières en France (Grosclaude 1988). L'incidence fromagère de ce particularisme a été étudiée. Les premiers travaux ont été réalisés en laboratoire sur des laits individuels de vaches présentant le variant $\mathrm{C}$ de la $\beta$-caséine $(\beta-C n C)$ ou le variant A $(\beta-\mathrm{CnA}$, variant fréquent dans la plupart des races), transformés en mini-fromages, selon une technologie de type pâte pressée cuite adaptée de celle du fromage de Beaufort. Le comportement des laits en cuve de fabrication, la protéolyse, la structure, la texture et la flaveur des fromages $\beta-\mathrm{Cn} C$ ont été comparés à ceux des fromages $\beta-\mathrm{Cn} \mathrm{A}$. Il apparaît que les fromages $\beta-\mathrm{Cn} C$, qui ont une faible teneur en matière grasse et une structure irrégulière, se caractérisent par une texture plus ferme et moins élastique que les fromages $\beta-\mathrm{Cn} \mathrm{A}$. Les fromages $\beta-\mathrm{Cn}$ $C$ ont un goût particulier et sont plus souvent notés piquants que les fromages $\beta-C n$ A (Delacroix-Buchet et Marie 1994, Marie et DelacroixBuchet 1994). Pour valider ces résultats, des fromages de Beaufort ont été fabriqués par un même fromager, simultanément dans deux cuves de 4501 . dans une coopérative des Alpes du Nord, au printemps, sur deux années consécutives, soit avec des laits contenant des proportions importantes $(80 \%$ ou plus) soit au contraire faibles $(15 \%) \mathrm{du}$ variant $\mathrm{C}$ de la $\beta$-caséine (tableau 3). Les laits utilisés provenaient de trois troupeaux dont les animaux avaient fait l'objet d'un typage génétique. Les analyses sensorielles des fromages affinés réalisées par un jury d'experts ne révèlent pas de différences importantes en ce qui concerne la texture des fromages. En revanche, les fromages réalisés avec le lait $\beta$-Cn C sont plus salés, ont un arôme plus intense, plus animal et plus citronné. Leur odeur est également jugée plus intense, plus piquante, plus diversifiée et plus lactée (Martin 1998).

Ces dernières décades, le génotypage des races caprines a montré l'existence, au locus de la caséine $\alpha_{\mathrm{s} 1}$, d'un vaste polymorphisme associé à des différences exceptionnelles du taux de synthèse de caséine (Boulanger et al 1984, Grosclaude et al 1987, Mahé et Grosclaude 1989). Onze allèles sont actuellement identifiés associés à 4 niveaux de synthèse définis comme 
Tableau 3. Incidence du variant $C$ de la caséine $\beta$ sur les caractéristiques physicochimiques et sensorielles de fromages de Beaufort (Martin 1998) (moyenne de 2 fabrications répétées 2 jours consécutifs).

\begin{tabular}{|c|c|c|c|}
\hline & Témoin & Essai & \\
\hline Variant $\mathrm{C}$ de la caséine $\beta(\%)$ & 13 & 88 & \\
\hline Gras/sec (\%) & 47,7 & 45,3 & ** \\
\hline$\beta$-caséine intacte $(\%)$ & 14,8 & 16,6 & \\
\hline Lipolyse (\%) & 0,36 & 0,41 & \\
\hline \multicolumn{4}{|l|}{ Saveur } \\
\hline Salée & 4,4 & 5,1 & ** \\
\hline \multicolumn{4}{|l|}{ Odeur } \\
\hline Intense & 4,1 & 4,7 & ** \\
\hline Diversifiée & 3,4 & 4,2 & ** \\
\hline Lait & 3,1 & 3,6 & ** \\
\hline \multicolumn{4}{|l|}{ Arôme } \\
\hline Intense & 5,1 & 5,8 & ** \\
\hline Animal & 2,3 & 3,0 & ** \\
\hline Citron & 1,5 & 1,8 & * \\
\hline
\end{tabular}

${ }^{*}: \mathrm{P}<0,05 ;{ }^{* *}: \mathrm{P}<0,01$.

« fort » (allèles $A, B_{1}, B_{2}, B_{3}, B_{4}$ et $C$ ), " moyen » $(\mathrm{E})$, « faible » $(\mathrm{F}, \mathrm{G})$ et « nul » $\left(\mathrm{O}_{1}, \mathrm{O}_{2}\right)$ (Grosclaude et Martin 1997). Cette découverte a été suivie de l'analyse des effets de ce polymophisme sur les propriétés des laits et des fromages (Grosclaude et al 1994). Les résultats montrent que les allèles conduisant à une réduction du niveau de synthèse des protéines, notamment les mutants défectifs $\mathrm{O}$ et $\mathrm{F}$, sont associés à une flaveur " chèvre " plus affirmée des laits et des fromages produits en milieu de lactation (avril-mai) tandis que l'allèle A est associé à des rendements fromagers plus élevés et à une texture plus ferme des fromages (tableau 4). Le même phénomène est observé que l'on compare des fromages à pâte pressée ou des fromages à pâte molle et croûte fleurie, plus traditionnels de la filière caprine, fabriqués avec les laits des deux classes d'allèles (Heil et Dumont 1993, Pirisi et al 1994, Vassal et al 1994, Delacroix-Buchet et al 1996, Lamberet et al 1996, Tziboula et al 1997, Pierre et al 1998). Dans la plupart de ces essais, les caractéristiques chimiques des fromages avant salage étaient semblables, en particulier leur extrait sec dégraissé. Cependant, au cours de l'affinage des fromages, les différences s'estompent. Elles sont maximales en milieu d'affinage pour des fromages type Gouda (Heil et Dumont 1993, Delacroix-Buchet et al 1996, Lamberet et al 1996, Pierre et al 1998).

Les recherches sur le polymorphisme des lactoprotéines ovines ne sont pas aussi nombreuses que chez la vache ou la chèvre. Malgré tout l'intérêt d'une

$\beta$-lactoglobuline. des données bibliographiques citées dans le texte).

${ }^{1}$ Acide 4-éthyloctanoique.

${ }^{2}$ Acide 4-méthyloctanoique.

\section{2 / Effet des caractéris- tiques physiologiques et de l'état sanitaire}

\section{1 / Etat sanitaire}

Les mammites sont les troubles sanitaires les plus fréquemment rencontrés dans les élevages laitiers. Ce sont des infections microbiennes de la mamelle qui sont à l'origine d'une augmentation forte de la concentration en cellules somatiques (CCS) du lait. Outre leur impact sur la qualité microbiologique du lait lié au transfert au lait des germes responsables de l'infection (dont certains comme Streptococcus agalactiae, Staphylococcus aureus, Escherichia coli...peuvent être pathogènes pour l'homme), les mammites sont également à l'origine de modifications importantes de la composition chimique du lait. Elles entraînent en général, au moins chez la vache, une diminution de la teneur en lactose, une altération de la membrane des globules gras favorisant la lipolyse, une diminution de la teneur en caséines, une augmentation de la teneur en protéines solubles et en enzymes ainsi qu'une modification des équilibres salins (Munro et al 1984, Coulon et al 2002). Ces effets résultent d'un dysfonctionnement de la glande mammaire entrainant un transfert accru de certains composés du sang vers le lait.

Les influences de la CCS des laits sur la coagulation et l'égouttage ainsi que sur les rendements fromagers ont été largement décrites par de nombreux auteurs aussi bien pour les laits de

Tableau 4. Incidence du type de variant (fort ou défectif) de la caséine $\alpha_{s 1}$ caprine sur les caractéristiques sensorielles des fromages au lait de chèvre (d'après compilation

\begin{tabular}{|l|c|c|}
\hline Variants de la caséine $\alpha_{\mathrm{s} 1}$ & Fort $(\mathrm{A})$ & Défectif $(\mathrm{F} / \mathrm{O})$ \\
\hline Acides gras des triglycérides & - & + \\
$-\mathrm{C}_{4: 0}, \mathrm{C}_{16: 0}, \mathrm{C}_{18: 1}, 4 \mathrm{EtC}_{8: 0} 1$ & + & - \\
$-\mathrm{C}_{8: 0}, \mathrm{C}_{10: 0}, \mathrm{C}_{12: 0}, \mathrm{C}_{14: 0}, \mathrm{C}_{18: 0}, 4 \mathrm{MéC}_{8: 0}{ }^{2}$ & & \\
\hline Laits & & - \\
- Teneur en caséine totale & + & - \\
- Teneur en matières grasses & + & + \\
- Activité lipasique et teneur en acides gras libres & - & + \\
\hline Fromages & & + \\
- Lipolyse initiale & - & + \\
- Acides gras libres : $\mathrm{C}_{6: 0}, \mathrm{C}_{8: 0}, \mathrm{C}_{9: 0}, \mathrm{C}_{10: 0}, 4 \mathrm{MéC}_{8: 0}, 4 \mathrm{EtC}_{8: 0}$ & - & - \\
- Arôme « chèvre » & - & + \\
- Fermeté & & + \\
\hline
\end{tabular}


vache (Munro et al 1984, Grandison et Ford 1986, Politis et Ng-Kwai-Hang 1988a et b, Barbano et al 1991, Auldist et al 1996, Cooney et al 2000) que pour les laits de chèvre (Galina et al 1996) ou de brebis (Pirisi et al 1996 et 2000b). Les laits présentant une CCS élevée coagulent lentement, se raffermissent et s'égouttent mal. Ils sont à l'origine d'une diminution du rendement fromager due à des pertes de protéines et de matières grasses dans le lactosérum. La teneur en eau des fromages correspondants est augmentée ainsi que les processus de protéolyse (Grandison et Ford 1986, O'Farrell et al 2002, Cooney et al 2000). Les auteurs ayant réalisé des fromages à partir de laits présentant des CCS croissantes ont observé une augmentation de la teneur en eau du fromage résultant du moins bon égouttage du caillé (Grandison et Ford 1986, Politis et NgKwai-Hang 1988b). Sur le plan des caractéristiques sensorielles des fromages, des résultats anciens synthétisés par Munro et al (1984) soulignent qu'aux CCS les plus élevées sont généralement associés une appréciation globale moindre et des défauts de texture ou de flaveur, de nature et d'importance variables selon le type de fromage. En réalisant des fromages Cheddar à partir de laits dont les CCS variaient entre 200000 et 2200000 cellules $/ \mathrm{ml}$, Grandison et al (1984) ont montré que l'augmentation de la CCS était à l'origine d'une diminution de la fermeté et de l'élasticité et d'une augmentation de l'adhésivité de la pâte, ces différences étant elles-mêmes corrélées à l'augmentation de la teneur en eau du fromage. Cet effet sur la texture des fromages a été confirmé plus récemment par Auldist et al (1996). En ce qui concerne la flaveur des fromages, la dépréciation généralement rapportée (Munro et al 1984) est rarement décrite : dans quelques études, les CCS élevées ont été associées à des défauts de goût liés à la lipolyse (Auldist et al 1996) tel que « rance » et « oxydé » ou à la protéolyse (Cooney et al 2000) tels que " amer ». Grandison et al (1984) ont par ailleurs mis en évidence une liaison positive entre la CCS et l'intensité de la flaveur totale ou l'intensité des flaveurs indésirables.

Chez la brebis, la comparaison de fromages obtenus avec les laits présentant une CCS $<500000$ ou $>1000000$ cellules/ml n'a pas permis de mettre en évidence de différences significatives d'un point de vue sensoriel (Pirisi et al 1996). Plus récemment, les travaux de Pirisi et al (2000b) ont également montré que la CCS n'affectait ni les caractéristiques rhéologiques, ni la lipolyse des fromages.

Chez la chèvre, les travaux de Jaubert et al (1996) suggèrent que la flaveur " chèvre " du lait pourrait être corrélée à la CCS : en classant 80 laits de chèvre provenant de 40 élevages de la région Poitou-Charentes en trois groupes homogènes et significativement différents en matière d'intensité de la flaveur " chèvre ", ces auteurs ont montré que les laits présentant la flaveur " chèvre » la plus prononcée étaient caractérisés en moyenne par une teneur en matière grasse plus faible, un niveau cellulaire et un niveau de lipolyse plus importants par rapport à ceux présentant une flaveur " chèvre " peu prononcée. Les différences de flaveur « chèvre » du lait s'expriment dans les fromages frais type Crottin mais s'estompent dans les fromages affinés qui présentent des niveaux de lipolyse plus élevés. Ce dernier résultat est confirmé par une étude récente (Morgan et Gaspard 1999) qui ne met pas en évidence d'effets significatifs du niveau de CCS sur les caractéristiques biochimiques et sensorielles de fromages lactiques de type buchette. Il semble donc que les facteurs liés à la technologie fromagère caprine, et notamment la conduite de l'affinage des fromages, permettent de minimiser le rôle des cellules somatiques.

\section{2 / Stade physiologique et fré- quence de traite}

Le stade physiologique des animaux est un facteur de variation majeur de différents constituants du lait : teneur et composition des matières grasses, teneurs en protéines, en minéraux ou en enzymes telles la plasmine (Coulon et al 1991, Dupont et al 1998). Ces variations sont à l'origine d'un effet fort du

Tableau 5. Effet du stade physiologique sur les caractéristiques sensorielles du fromage (cas du saint-nectaire) (Coulon et al 1998).

\begin{tabular}{|l|c|c|c|c|}
\hline Stade & début & milieu & fin & \\
\hline Jours de lactation & $15-45$ & $150-230$ & 300 & \\
\hline Rendement $^{1}$ & 13,8 & 14,1 & 15,5 & $* *$ \\
$\mathrm{pH}$ & 5,48 & 5,47 & 5,67 & $* *$ \\
Gras/sec & 50,0 & 52,8 & 53,0 & $* *$ \\
Indice de jaune & 30,3 & 28,7 & 27,5 & $* *$ \\
\hline Texture ferme & 5,1 & 5,0 & 4,3 & $* *$ \\
Odeur agréable & 4,9 & 5,5 & 4,6 & $* *$ \\
Persistance du goût & 5,4 & 5,0 & 6,0 & $*$ \\
Intensité du goût & 5,0 & 5,0 & 5,8 & $*$ \\
\hline
\end{tabular}

${ }^{1} \mathrm{~kg}$ de caillé obtenu avec $100 \mathrm{~kg}$ de lait.

${ }^{*}: \mathrm{P}<0,05 ;{ }^{* *}: \mathrm{P}<0,01$. stade physiologique sur la coagulation $\mathrm{du}$ lait et sur les rendements fromagers (Martin et Coulon 1995).

Dans les zones où la production est très saisonnière, les fromages produits lorsque les animaux sont en fin de lactation sont fréquemment décrits comme étant plus humides, se protéolysant plus rapidement et ayant une texture moins ferme et moins élastique avec des défauts de goût prononcés (O'Keeffe 1984, Lucey et al 1992, Martin et Coulon 1995, Lucey 1996). Dans ces études, les effets attribués au stade de lactation étaient cependant confondus avec ceux de la saison, de l'alimentation ou de la numération cellulaire des laits souvent plus élevée en fin de lactation.

Kefford et al (1995) et Auldist et al (1996) se sont efforcés de décrire l'effet du stade de lactation parallèlement à ceux de l'alimentation ou de la numération cellulaire. Ils concluent tous deux que la dépréciation de la qualité des fromages observée en fin de lactation est très largement limitée lorsque 1'alimentation et la numération cellulaire sont bien maîtrisées. En conditions contrôlées de production du lait et de fabrication de fromages Saint-Nectaire, Coulon et al (1998) ont quantifié l'effet propre du stade de lactation, étudié entre 26 et 298 jours (tableau 5). Les fromages réalisés avec des laits de début de lactation ont été plus jaunes que les autres et ont présenté un gras/sec inférieur. Les fromages réalisés avec des laits de fin de lactation ont été plus collants, plus fondants, moins fermes et moins granuleux que ceux de début ou de milieu de lactation. Leur goût a été plus intense, plus persistant, plus acide et plus amer. Globalement, ils ont été moins appréciés que les autres. Ces écarts étaient probablement liés à une protéolyse plus intense sur les fromages de fin de lactation. Si ces 
écarts sont importants, ils ne sont cependant sensibles qu'en toute fin de lactation. En pratique, ce facteur n'aura donc des conséquences que dans des conditions particulières de conduite des vêlages des animaux (très groupés) ou lorsque d'autres facteurs tels que des CCS élevées sont associés aux stades de lactation avancés.

La traite des vaches une seule fois par jour (monotraite) est à l'origine d'une diminution de la production laitière (de l'ordre de 20 à $30 \%$ selon les essais), et d'une augmentation des taux butyreux $(+2,8 \mathrm{~g} / \mathrm{kg})$ et protéiques $(+1,5 \mathrm{~g} / \mathrm{kg})$ (Rémond et Pomiès, 2004). Dans un essai réalisé en conditions expérimentales en fabrication de fromages de Cantal, ces modifications de la composition chimique du lait n'ont été accompagnées d'aucune modification significative des caractéristiques sensorielles du fromage (Pomiès et al 2003).

\section{3 / Effet des facteurs ali- mentaires}

Jusqu'à présent, les travaux relatifs à l'effet de l'alimentation des animaux sur la qualité des produits laitiers ont surtout concerné l'influence du niveau des apports nutritifs et des grands types de régime sur les teneurs en composés majeurs du lait (protéines et matières grasses) (Sutton 1989, Coulon et Rémond 1991). Les variations de ces teneurs peuvent avoir des conséquences considérables sur les rendements fromagers (Verdier-Metz et al 2001) mais aussi sur certaines caractéristiques sensorielle, et en particulier la texture (Martin et al 1997). En revanche, en dehors de l'effet bien connu de certaines plantes (crucifères, ail, oignon) sur la flaveur du lait ou du fromage (Forss 1992, Urbach 1990), l'effet propre de la nature de l'alimentation et en particulier des fourrages (mode de conservation, qualité de conservation, diversité floristique) a été peu abordé. Pourtant, de nombreuses observations empiriques confèrent à ce facteur des effets sur les caractéristiques sensorielles des produits (Urbach 1990). Ainsi, certains fromagers observent fréquemment des différences de qualités sensorielles des fromages selon la nature des fourrages offerts aux animaux. Ces observations ont pu être appuyées par des études globales destinées à analyser la diversité des caractéristiques sensorielles d'un type de fromage et à mettre en parallèle cette diversité avec les conditions de production du lait et des fromages.
Ainsi, chez des producteurs de Reblochon fermier, Martin et Coulon (1995) ont montré que dans certaines conditions de fabrication fromagère, des différences de caractéristiques sensorielles pouvaient être associées à des natures différentes de fourrage (foins ou pâtures). De même, en zone Comté, Monnet et al (2000) ont mis en évidence des associations entre des typologies floristiques des pâturages et sensorielles des fromages et Bérodier (1997) a montré qu'une diversité botanique pouvait être associée à des arômes plus nombreux et plus variés des fromages. Dans des fromageries privées, des différences de caractéristiques sensorielles ont été observées entre des fromages élaborés à partir de laits issus d'exploitations différant par leur système de conduite des animaux (Martin et al 2003, Agabriel et al 2004). Parallèlement, des travaux expérimentaux ont été entrepris pour analyser l'effet spécifique de la nature des fourrages, de son mode de conservation et de sa diversité botanique.

\section{1 / Effet de la nature de la ration et du mode de conserva- tion de l'herbe}

L'effet de l'utilisation de l'ensilage de maïs dans la ration a été testé dans des travaux qui ont comparé des fromages obtenus avec du lait de vaches nourries exclusivement avec de l'ensilage de maïs ou avec des rations à base d'herbe distribuée sous forme de foin (Verdier et al 1995) ou d'ensilage (Houssin et al 2002, Hurtaud et al 2004). Comparativement à l'herbe, quel que soit son mode de conservation, le maïs conduit à des fromages plus blancs, légèrement plus fermes et globalement moins appréciés des dégustateurs. Les observations réalisées en exploitations par Toso et Stephanon (2001) confirment ces résultats expérimentaux. En comparant des fromages Montasio fabriqués à partir de lait provenant de groupes d'exploitations utilisant ou non de l'ensilage de maïs, ces auteurs ont montré qu'après 2 mois d'affinage les fromages réalisés à partir du lait des exploitations sans ensilage étaient préférés aux autres, bien qu'après 6 et 12 mois d'affinage les différences s'atténuent. Chez la chèvre, des résultats récents montrent que le foin de luzerne, comparativement à l'ensilage de maïs, conduit à des fromages ayant une flaveur plus intense (Gaborit et al 2002). Chez la brebis, l'utilisation de l'ensilage de maïs a conduit à une augmentation du nombre de spores butyriques mais n'a pas eu de conséquences sur les caractéristiques sensorielles des fromages (Cavani et al 1991).

La question de la conservation de l'herbe sous forme d'ensilage est depuis longtemps un sujet de débats au sein des filières fromagères d'AOC. Certains défauts spécifiques peuvent être observés avec des ensilages mal conservés (Urbach 1990, Forss 1992), en particulier en fabrication de pâte pressée cuite où la présence de spores butyriques dans l'ensilage et dans le lait peut conduire à des problèmes importants sur les fromages affinés (gonflements tardifs, mauvais goût et odeur Demarquilly 1998). Lorsque les ensilages sont de bonne qualité les résultats semblent différents. Nous avons réalisé un essai (Verdier-Metz et al 1998) où l'herbe d'une même parcelle a été récoltée le même jour et conservée soit sous forme d'ensilage (avec adjonction d'un conservateur acide) soit sous forme de foin (séché en grange) (tableau 6). Dans les deux cas, la qualité de conservation a été excellente et les apports nutritifs offerts aux animaux ont été calculés pour être équivalents. Des fromages de Saint-Nectaire ont été fabriqués dans une fromagerie expérimentale à partir du lait des vaches ayant consommé l'un ou l'autre des types de fourrages. Les fromages réalisés à partir du lait d'ensilage ont été plus jaunes et légèrement plus amers que ceux réalisés à partir du lait de foin. Les autres caractéristiques chimiques et sensorielles des fromages n'ont pas été différentes entre les deux traitements. $\mathrm{Ce}$ résultat expérimental a été confirmé par des observations en fermes (Agabriel et al 1999). Ces travaux montrent que lorsque la conservation du fourrage est correctement réalisée et que les rations correspondantes sont correctement élaborées, le mode de conservation au sens strict n'a qu'un effet limité, en dehors de la couleur de la pâte, sur les caractéristiques sensorielles du fromage. Il est cependant possible que les effets de la conservation de l'herbe sous forme d'ensilage soient variables selon le type de fromage. Dans un essai récent (Verdier-Metz et al non publié), la distribution d'ensilage d'herbe comparativement à du foin a entraîné des différences sensorielles plus significatives sur des fromages de type Cantal que sur des fromages de type SaintNectaire.

Par contre, d'importantes différences de caractéristiques sensorielles ont été observées entre des fromages selon que le lait provenait de vaches recevant une 
Tableau 6. Effet de la conservation du fourrage sur les caractéristiques physico-chimiques et sensorielles des fromages (Verdier-Metz et al 1998 et 2000a).

\begin{tabular}{|l|c|c|c|c|}
\hline \multirow{2}{*}{ Ration } & \multicolumn{2}{c|}{ Essai 1 } & \multicolumn{2}{c|}{ Essai 2 } \\
\cline { 2 - 5 } & $\begin{array}{c}\text { Ensilage } \\
\text { d'herbe }\end{array}$ & Foin & $\begin{array}{c}\text { Ensilage } \\
\text { d'herbe }\end{array}$ & Pâturage \\
\hline Lait & & & & \\
Taux butyreux (g/kg) & 35,3 & 36,3 & 36,4 & 37,1 \\
Taux protéique (g/kg) & 33,6 & 33,5 & $28,7^{* *}$ & 33,6 \\
\hline Fromage & & & & \\
Extrait sec (\%) & 54,6 & 54,8 & 52,6 & 52,7 \\
Gras/sec & 52,3 & 52,0 & $54,1^{* *}$ & 50,5 \\
Indice de jaune & $32,9^{* *}$ & 29,9 & $24,7^{* *}$ & 30,5 \\
Texture ferme & 4,6 & 4,5 & $4,3^{* *}$ & 3,4 \\
Texture collante & 3,1 & 3,3 & $4,1^{*}$ & 3,5 \\
Intensité du goût & 5,4 & 5,3 & $5,0^{* *}$ & 5,6 \\
Intensité de l'odeur & 5,2 & 5,2 & 4,6 & 4,4 \\
Odeur piquante & - & - & $1,3^{* *}$ & 0,2 \\
Amertume & 3,5 & 3,2 & $1,5^{*}$ & 1,9 \\
\hline
\end{tabular}

${ }^{*}: \mathrm{P}<0,05 ;{ }^{* *}: \mathrm{P}<0,01$.

ration hivernale (à base de foin et d'ensilage d'herbe) ou conduites au printemps sur un pâturage de montagne (tableau 6). Les fromages de SaintNectaire issus du lait de pâturage ont été plus jaunes, ont présenté une texture moins ferme, un goût plus intense et une odeur moins piquante, moins aigre et moins fruitée que ceux issus des laits hivernaux (Verdier-Metz et al 2000a). Des résultats voisins ont été obtenus par Buchin et al (1998) dans un essai comparant des fromages de Comté réalisés à partir de lait produit par des vaches recevant des rations à base de foin ou conduites sur un pâturage de printemps. Ces travaux confirment les observations des producteurs fermiers lors de la mise à l'herbe des vaches laitières. Récemment, Carpino et al (2004a) ont montré, en conditions de pâturage sicilien, qu'il suffisait de $3 \mathrm{~kg}$ MS d'herbe ingérés en plus d'une ration complète (à base de foin, d'ensilage de maïs et de concentrés) pour que les fromages soient plus jaunes, moins fermes, avec des odeurs plus « herbacées » et « florales ». En Norvège, d'après d'anciennes études conduites sur chèvres, il semble que la flaveur "chèvre " soit moins prononcée avec une alimentation à l'étable qu'au pâturage (Korvald 1958) alors que Ronningen (1965) montre la tendance inverse.

\section{2 / Effet de la composition botanique de l'herbe}

$\mathrm{Au}$ cours des dernières années, plusieurs essais ont été réalisés en Europe pour décrire et analyser l'effet de la diversité botanique des fourrages offerts aux animaux (sous forme pâtu- rée ou conservée) sur les caractéristiques sensorielles de différents types de fromage, généralement à pâte pressée cuite (figure 1).

Un premier essai (Buchin et al 1999), réalisé chez un producteur d'Abondance fermier, a consisté à comparer les caractéristiques de fromages fabriqués lorsque son troupeau a pâturé successivement les deux versants d'un même alpage (dont la composition botanique était très différente), puis est revenu sur une zone du premier versant mise en défens lors du premier passage. Les deux séries de fromages réalisés lorsque les animaux pâturaient le versant sud de l'alpage s'opposent aux frotats obtenus dans les essais cités dans le texte. mages du versant nord. Les différences les plus importantes concernent la texture : les fromages du versant nord ont été moins fermes, plus fondants et plus pâteux. Sur le plan des arômes et des saveurs, les fromages du versant nord ont été globalement plus "corsés 》 (plus salés et amers, avec des arômes aigre, d'étable et de sueur) et ceux du versant sud plus « doux », avec des arômes de fruits plus développés.

Un deuxième essai (Martin et al 2001) a été réalisé en alpage chez un producteur de Beaufort, selon le même principe que l'essai 1 . Il a permis de montrer des différences concernant essentiellement la flaveur : les Beaufort des pelouses « alpines » (> $2200 \mathrm{~m}$ ) ont été plus salés, plus piquants et plus acides que ceux des pelouses « moyennes ». Ils ont présenté des arômes plus intenses et plus épicés.

Un troisième essai (Verdier-Metz et al 2002a) a consisté à fabriquer un fromage à pâte pressée selon une technologie Saint-Nectaire dans une fromagerie expérimentale à partir de lait de vaches conduites dans les mêmes conditions (traite, état sanitaire, apports nutritifs, logement...) mais recevant du dactyle (sous forme de foin) ou de la prairie naturelle d'Auvergne (en vert ou sous forme de foin). Comparativement aux fromages de foin de dactyle, les fromages de prairie naturelle ont été moins fondants et moins amers, avec des odeurs de rance et de moisi moins développées. Lorsque la prairie naturelle a été offerte en vert, les fromages ont

Figure 1. Différenciation des caractéristiques sensorielles (flaveur et texture) de différents fromages selon la nature des fourrages. Représentation schématique des résul-

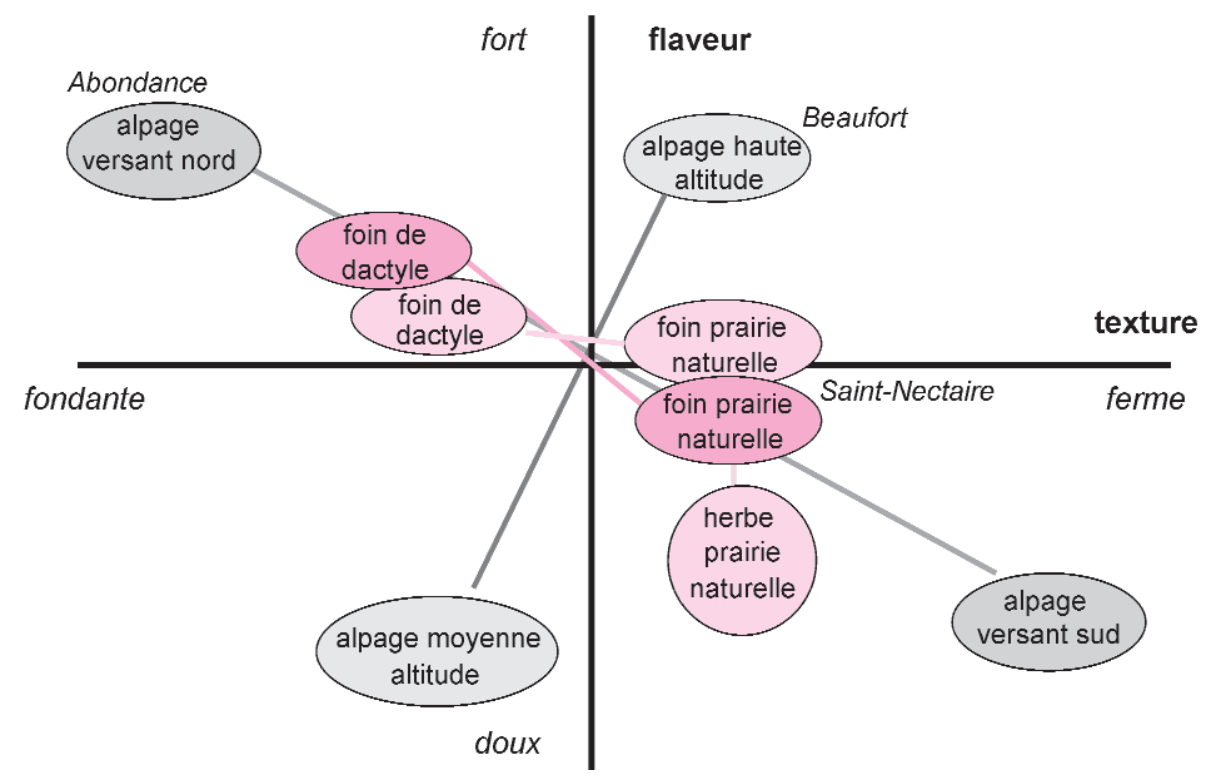


été plus salés et moins aigres que lorsqu'elle était offerte sous forme de foin.

Enfin, dans un essai récent (Bugaud et al 2002), réalisé chez trois producteurs fermiers d'Abondance, il a été clairement montré qu'à côté de différences d'un producteur à l'autre, il existait des écarts importants pour un même producteur selon les caractéristiques des prairies pâturées. Si les écarts les plus importants opposent les prairies de plaine à celles de montagne, il subsiste aussi une variabilité au sein des pelouses d'alpage. Les différences les plus importantes ont concerné la texture des fromages, plus cohésive, élastique et déformable en plaine qu'en montagne, et plus sableuse sur les pelouses nitrophiles et nivales que sur les pelouses humides. Ces résultats confirment et précisent ceux obtenus par Bosset et al (1999) sur des fromages de type Gruyère produits à partir de laits de plaine ou de montagne. Dans cet essai, les fromages de montagne ont présenté une flaveur plus intense que ceux de plaine. Ils ont en particulier été jugés plus «animal » et plus « piquant ».

\section{4 / Origine des différences sensorielles}

Les modifications des caractéristiques sensorielles des fromages sous l'effet des facteurs de production dépendent de plusieurs types de mécanismes : 1) passage sans modification dans le lait et le fromage de molécules présentes dans les aliments, 2) modification de la composition des protéines et des matières grasses altérant leurs propriétés, 3) passage dans le lait d'enzymes endogènes modifiant la protéolyse et la lipolyse durant l'affinage et 4) modification de l'écosystème microbien du lait et de son activité.

\section{1 / Transfert direct}

Un certain nombre des caractéristiques sensorielles du fromage peuvent être dues à certains constituants du lait, directement issus de l'alimentation, et des fourrages en particulier. La plupart des crucifères, quand elles sont ingérées en grandes quantités, conduisent à des défauts de flaveur dans les produits laitiers dus à des composés volatiles (allyl isothiocyanate en particulier) libérées pendant la digestion dans le rumen (Urbach 1990). La couleur dépend aussi directement de la composition des fourrages. Le lait contient des quantités plus ou moins importantes de pigments. Le plus connu est le carotène, présent en grandes quantités dans les fourrages verts et qui contribue à la coloration jaune des produits laitiers. Très sensible aux ultra-violets, le carotène est détruit lors du séchage et de la conservation des fourrages de manière d'autant plus forte que l'exposition à la lumière est importante (Park et al 1983). La nature de l'alimentation a donc un effet marqué sur sa teneur dans le lait et donc sur la couleur des beurres et des fromages (Waghorn et Knight 1992, Houssin et al 2002, Coulon et Priolo 2002) (tableau 7). Ainsi les fromages réalisés avec des laits de printemps sont-ils beaucoup plus jaunes que ceux réalisés avec des laits d'hiver. L'hiver, les fromages réalisés avec des laits d'ensilage d'herbe sont plus jaunes que ceux réalisés avec des laits de foin, surtout si ces derniers sont restés longtemps au sol. L'ensilage de maïs, très pauvre en carotènes, conduit à des fromages très blancs (Verdier et al 1995).

Une autre origine directe de l'effet de la composition botanique des fourrages sur les caractéristiques sensorielles des fromages, évoquée depuis longtemps (Dumont et Adda 1978), concerne l'effet des terpènes. Ces molécules, spécifiques du monde végétal ont des propriétés odorantes reconnues à l'état concentré. Elles sont beaucoup plus abondantes dans certaines espèces, et en particulier les dicotylédones (Mariaca et al 1997, Cornu et al 2001). Ces molécules passent très rapidement dans le lait (Viallon et al 2000) et se retrouvent dans le fromage, en quantité beaucoup plus importante lorsque les animaux consomment, en vert ou sous forme conservée, des fourrages de prairie naturelle riches en dicotylédones, généralement caractéristiques des zones de montagne, comparativement à des alimentations à base d'aliment concentré (Moio et al 1996), ou de fourrages monospécifiques (Bosset et al 1994, Buchin et al 1998, Viallon et al 1999, Bugaud et al 2002, Carpino et al 2004b). Cependant, si ces molécules peuvent constituer des outils efficaces de marquage de l'origine des fromages (Bosset et al 1999, Cornu et al 2001), il ne semble pas que la modification de leur teneur dans les fromages soit suffisante pour s'accompagner d'effet direct important sur la flaveur des fromages (Moio et al 1996, Verdier-Metz et al 2000a, Bugaud et al 2002).

\section{2 / Modifications des protéines et de la matière grasse}

Une partie des effets des facteurs de production sur les caractéristiques sensorielles des fromages est due à des modifications de la composition des protéines du lait. La teneur en eau élevée des fromages issus de laits à fortes numérations cellulaires peut ainsi être en partie expliquée par la faible aptitude à la coagulation et à l'égouttage de ces laits liée à l'augmentation des protéines solubles du lait et à la modification des équilibres salins (Coulon et al 2002).

Les différences de texture observées entre fromages fabriqués avec des laits d'animaux de génotype de caséines différents apparaissent dès la coagulation du lait. Elles s'expliquent en général par des différences de structure des micelles de caséines (diamètre, proportion de caséine $\kappa$, ratio des caséines $\alpha_{\mathrm{s} 1}$ et $\beta$, teneur en résidus phosphosérine, minéralisation calcique) qui engendrent à leur tour des variations de rétention de la matière grasse, de l'eau et des minéraux dans le réseau de caséines. Par voie de conséquence, la microstructure et les propriétés rhéologiques des caillés fromagers sont modifiées. Plus la taille des micelles de caséines est réduite, plus le réseau de caséines du gel présure est dense et sa fermeté importante (Niki et Arima 1984, Remeuf et al 1991) ce qui améliore la rétention de matière grasse dans le coagulum. C'est le cas avec l'association des variants $B$ de la $\kappa$-caséine et de la $\beta$-caséine en race bovine Normande (Delacroix-Buchet et al 1993, NuytsPetit et al 1997) ou avec le variant fort A de la caséine $\alpha_{\mathrm{s} 1}$ (/ variants défectifs) chez la chèvre (Remeuf 1993) ou encore avec le variant $C$ de la caséine $\alpha_{\mathrm{s} 1}$ chez la brebis (Pirisi et al 1999b). L'exemple du variant $C$ de la $\beta$-caséine en race bovine Tarentaise est une bonne illustration des mécanismes qui peuvent être à l'origine des différences de

Tableau 7. Teneurs en carotènes des fourrages, des laits correspondants et coloration jaune des fromages (Coulon et Priolo 2002).

\begin{tabular}{|l|c|c|c|c|}
\hline \multicolumn{1}{|c|}{ Fourrages } & $\begin{array}{c}\text { Foin séché } \\
\text { au sol }\end{array}$ & $\begin{array}{c}\text { Foin séché } \\
\text { en grange }\end{array}$ & $\begin{array}{c}\text { Foin + ensilage } \\
\text { d'herbe }\end{array}$ & $\begin{array}{c}\text { Pâturage } \\
\text { de printemps }\end{array}$ \\
\hline Carotènes des fourrages $(\mathrm{g} / \mathrm{kg} \mathrm{MS})$ & 10 & 20 & 45 & 85 \\
Carotènes du lait $(\mu \mathrm{g} / \mathrm{l})$ & 75 & 80 & 130 & 220 \\
Indice de jaune du fromage & 20 & 25 & 28 & 30 \\
\hline
\end{tabular}


texture observées. Les micelles de caséine des laits $\beta$-Cn $C$ comparées à celles des laits témoins $\beta$-Cn A sont de grand diamètre $(+57 \%)$. Ils sont aussi pauvres en calcium (-14\%), en raison d'un rapport caséines $\alpha_{\mathrm{s}} / \beta$ plus faible et d'une moindre phosphorylation du variant $\mathrm{C}$. Il en résulte un comportement à la coagulation par la présure atypique (formation d'un réseau lâche et fragile), se traduisant par l'obtention d'un caillé moins ferme (- $33 \%$ ), avec des pertes de matière grasse importantes dans le lactosérum de fromagerie. Ces observations expliquent que les fromages $\beta-\mathrm{Cn} \mathrm{C}$, qui sont moins gras avec une microstructure irrégulière, se caractérisent par une texture plus ferme et moins élastique que les fromages $\beta-\mathrm{Cn}$ A (Delacroix-Buchet et Marie 1994).

Le polymorphisme des lactoprotéines se traduit aussi par des substitutions ou des délétions plus ou moins importantes d'acides aminés dans la séquence des protéines qui peuvent affecter la cinétique et les produits de protéolyse des caséines et engendrer des modifications supplémentaires des caractéristiques des fromages. C'est le cas pour l'hydrolyse par la plasmine du variant $\mathrm{C}$ de la $\beta$-caséine dans le Beaufort (Marie et Delacroix-Buchet 1994, Papoff et al 1995) et par la chymosine des variants $\mathrm{F}$ (chez la chèvre) ou $\mathrm{D}$ (chez la brebis) de la caséine $\alpha_{\mathrm{S}}$ (Pirisi et al 1994 et 1999b, Trujillo et al 1997). L'hydrolyse par la plasmine des variants $A$ et $C$ de la caséine $\beta$ conduit aux mêmes types de peptides mais en quantités différentes, ce qui peut être à l'origine des différences de flaveurs observées entre fromages issus de laits de différents haplotypes (Marie et Delacroix-Buchet 1994). Chez la chèvre, le variant $F$ de la caséine $\alpha_{\mathrm{s} 1}$ présente une hydrophobicité et des propriétés structurantes plus marquées que le variant $A$, ce qui pourrait expliquer les différences de cinétique de dégradation des caséines, de texture et de flaveur dans les fromages fabriqués avec des laits de chèvre A et $\mathrm{F}$ (Pirisi et al 1994, Delacroix-Buchet et al 1996, Lamberet et al 1996).

La composition de la matière grasse du lait (longueur de la chaîne carbonée et degré d'insaturation), et donc du fromage, dépend du stade de lactation (Requena et al 1999) mais aussi et surtout de l'alimentation des animaux (Chilliard et al 2000). Elle peut être à l'origine des différences de texture et/ou de flaveur des fromages (Buchin et al 1999, Collomb et al 1999, Bugaud et al 2002). Bugaud et al (2002) ont observé une relation étroite entre la déformation à la fracture du fromage et la teneur en acides gras longs insaturés $\mathrm{du}$ lait (figure 2). Le point de fusion plus faible de ces acides conduit à des matières grasses plus fluides et donc à des fromages plus souples. Par ailleurs, certains acides gras peuvent être dégradés par les enzymes microbiennes lors de l'affinage du fromage pour donner des composés responsables d'arômes dans le fromage (Keen et Wilson 1992, Urbach 1997). Enfin, des travaux récents ont montré que les propriétés des globules gras du lait pouvaient modifier les caractéristiques physicochimiques et sensorielles (fermeté, élasticité, couleur) des fromages de type Camembert (Michalski et al 2003). Or il est possible que les propriétés des globules gras du lait soient en partie sous la dépendance de facteurs alimentaires et/ou génétiques (Munro et al 1984, Peyraud non publié).

\section{3 / Effet des enzymes endogè- nes}

La teneur et l'activité des enzymes du lait dépendent en partie des facteurs de production. C'est le cas en particulier pour la plasmine, une protéase endogène provenant du sang, résistante à la chaleur et qui joue un rôle important au cours de l'affinage des fromages à pâte pressée cuite.

Les différences de texture observées entre des fromages issus de lait de milieu ou de fin de lactation peuvent ainsi être reliées à l'augmentation de la protéolyse en fin de lactation comme le montre l'augmentation du $\mathrm{pH}$ et de la teneur en $\gamma$ caséines dans les fromages (Coulon et al 1998). Cette protéolyse est due à la plasmine dont l'activité augmente en fin de lactation (Benslimane et al 1990), en particulier lorsque les numérations cellulaires sont élevées (Auldist et al 1996). Les différences de texture observées entre fromage de vallée et de montagne dans l'essai de Bugaud et al (2001) ou entre versant nord et sud d'un même alpage (Buchin et al 1999) sont aussi à relier à des teneurs en plasmine dans le lait très variable d'une situation à l'autre.

L'augmentation de la teneur et de l'activité de cette enzyme dans le lait dans certaines situations physiologiques ou alimentaires pourrait être due à une augmentation de la perméabilité cellulaire du tissu mammaire liée à une infection bactérienne (mammite) (Andrews 1983, Grandison et Ford 1986), à l'involution des cellules mammaire (en fin de lactation) ou à l'ingestion d'espèces particulières (renoncules), présentes uniquement dans certains types de prairies.

L'impact de laits de mammite sur la texture et la flaveur des fromages est en partie lié à un accroissement des activités enzymatiques de ces laits. Il a été récemment démontré que 1'addition de lait de mammite à du lait de fromagerie avait des effets très similaires à ceux de l'addition de plasmine exogène (O'Farrell et al 2002). Cela reflète le niveau plus élevé en plasmine et en enzymes protéolytiques cellulaires des laits riches en CCS (Andrews 1983, Grandison et Ford 1986) et la présence dans les

Figure 2. Relation entre la texture du fromage et la composition en matières grasses du lait (Bugaud et al 2002).

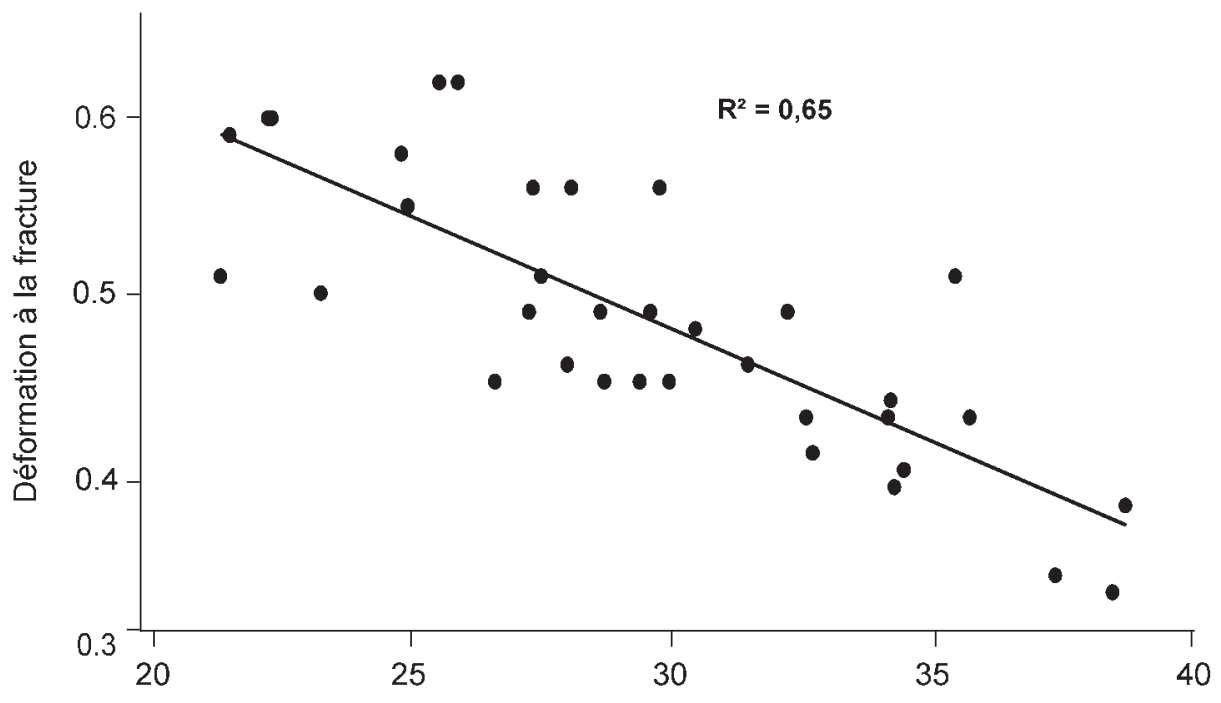

Acides gras longs insaturés du lait (en \%) 
CCS d'un activateur du plasminogène (Zachos et al 1992).

Des modifications du niveau de lipolyse des laits et des fromages ont également pu être observées selon les génotypes des caséines des animaux. Les mécanismes physiologiques en cause restent encore à élucider. Ces modifications permettent cependant de comprendre que des différences de caractéristiques aromatiques typiquement liées à la matière grasse laitière soient observées en comparant des produits sélectionnés à partir de caractéristiques génétiques des lactoprotéines. En race bovine Tarentaise, les Beaufort fabriqués avec du lait de génotype $\beta-\mathrm{Cn} C$ sont plus lipolysés et présentent un goût piquant et une odeur plus intense (Martin 1998). Chez les caprins, les laits des génotypes $\alpha_{\mathrm{s} 1}$ défectifs ( $\mathrm{F}$ ou $\mathrm{O}$ ) présentent en milieu de lactation une activité de la lipoprotéine lipase plus forte que les laits des génotypes $\alpha_{\mathrm{s} 1}$ fort (A) et ils ont une flaveur " chèvre " plus intense puisqu'elle est spécifiquement liée à la libération d'acides gras ramifiés en $\mathrm{C}_{8}$ (Woo et Lindsay 1984, Ha et Lindsay 1991 a et b, Lamberet et al 1996, Pierre et al 1998, Le Quéré et al 1998, Delacroix-Buchet et Lamberet 2000 a et b). Les caractéristiques sensorielles spécifiques des fromages issus de laits de fin de lactation peuvent aussi être dues à l'augmentation de la lipolyse du lait à cette période (Chazal et Chilliard 1986). Cette lipolyse n'est pas due à l'augmentation de la concentration en lipoprotéine-lipase, mais essentiellement à la modification de la structure du globule gras (Chilliard et al 2003).

Figure 3. Relation entre l'abondance en monoterpènes du lait et la présence de composés soufrés dans le fromage affiné (Bugaud et al 2002).

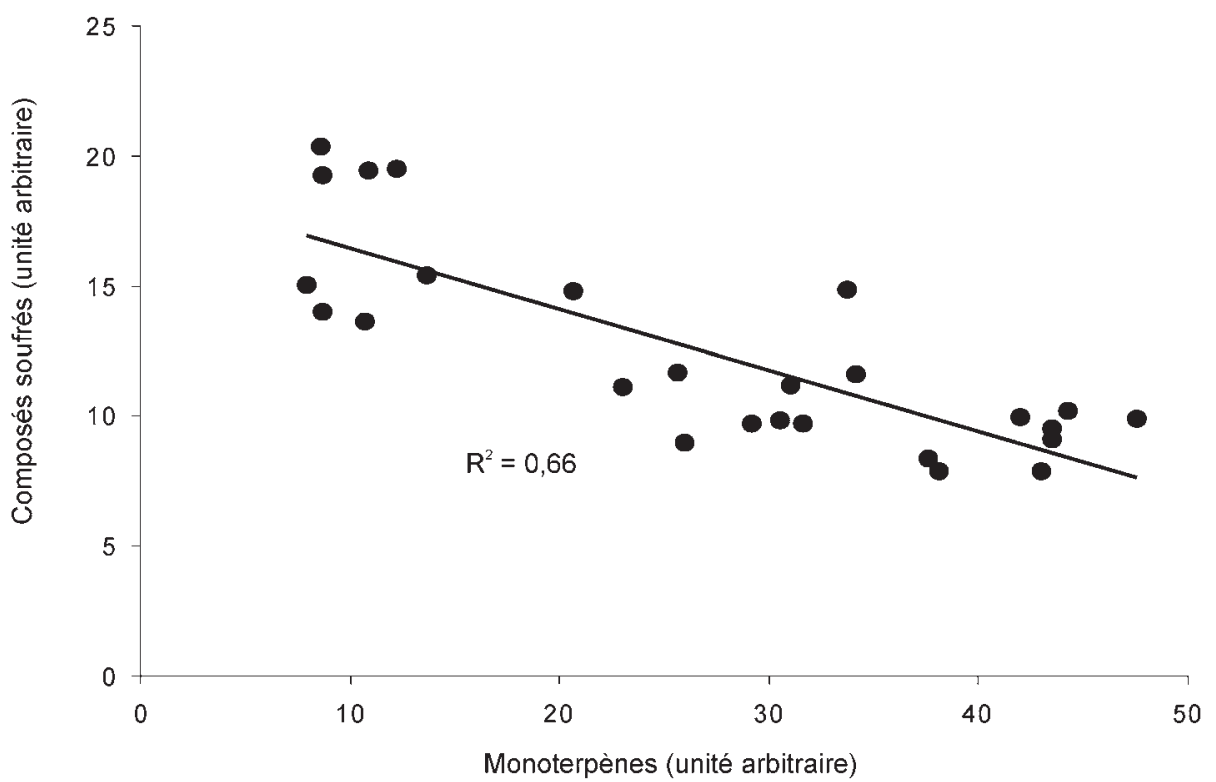

Enfin, concernant l'effet des laits de fin de lactation ou présentant une numération cellulaire élevée, Klei et al (1998) ont émis l'hypothèse que la croissance des bactéries lactiques pouvait être inhibée par les composés antibactériens présents dans les cellules somatiques, contribuant ainsi à des modifications des caractéristiques des fromages.

\section{Conclusion}

et al 2001, Duthoit 2003) pourrait être due à l'alimentation des animaux. Il a été récemment suggéré que les terpènes, dont on connaît bien les variations dans le lait selon la nature des fourrages consommés, pouvaient avoir un effet indirect sur les caractéristiques sensorielles des fromages en modifiant la dynamique de l'écosystème microbien durant la fabrication fromagère et l'affinage. Cette hypothèse résulte d'observations indirectes concernant l'existence de corrélation négative (figure 3 ) entre la teneur en terpènes et en composés volatils des fromages (composés soufrés en particulier) issus de la protéolyse microbienne (Buchin et al 1999, Bugaud et al 2002, Martin et al 2002).

Par ailleurs, les travaux récent de Verdier-Metz et al (2002b) suggèrent que certains effets des régimes sur les propriétés sensorielles des fromages pourraient avoir une origine microbienne : ainsi, sur du fromage de Cantal, des différences de flaveur marquées entre deux régimes alimentaires observées sur des fromages au lait cru disparaissent lorsque le lait est pasteurisé.

Les caractéristiques des fromages affinés dépendent de nombreux facteurs technologiques (mis en œuvre lors de la fabrication fromagère et/ou durant l'affinage). Lorsque ces facteurs ne sont pas suffisamment contrôlés, il est difficile de mettre en évidence et d'interpréter les effets éventuels des facteurs de production. La majorité des essais rapportés dans cette synthèse ont été conduits dans des conditions de fabrication fromagère contrôlées, en particulier au niveau de l'affinage. Les résultats qui en sont issus permettent donc de montrer que les caractéristiques des animaux et de leur conduite peuvent modifier sensiblement les propriétés sensorielles des fromages. Leurs effets peuvent apparaître à différentes étapes de l'élaboration du fromage (dès le moulage ou seulement durant l'affinage). Ces effets varient selon le type de technologie fromagère et peuvent dépendre des pratiques de traitement du lait mises en œuvre. Ainsi, un écrémage partiel visant à standardiser le rapport matières grasses/protéines $\mathrm{du}$ lait fait pratiquement disparaître l'effet de la race sur la texture du fromage, puisque cet effet est justement largement lié aux différences de ce rapport d'une race à l'autre. De même, le traitement thermique du lait semble masquer les effets de l'alimentation sur la flaveur du fromage. Il est donc vraisemblable que certaines pratiques de fabrication fromagère soient plus aptes à permettre l'expression de l'effet des facteurs de production que d'autres. Cependant, la validation de cette hypothèse et la quantification de ces interactions restent à mettre en œuvre.

Ces effets sont dus à la présence dans la matière première de molécules ou de structures spécifiques issues directement de l'alimentation (carotènes, terpènes) ou produits par l'animal (plasmine, acides gras, structure des micelles de caséines) en raison de ses caractéristiques génétiques ou physio- 
logiques ou sous l'effet d'une alimentation spécifique. Certaines de ces molécules (terpènes, carotènes, acides gras) peuvent par ailleurs être utilisées comme traceurs de l'alimentation (Martin et al 2002, Prache et al 2002) et/ou conférer des propriétés nutritionnelles spécifiques au produit (Chilliard et al 2001).
Ces résultats constituent pour les filières fromagères et en particulier pour les filières de fromages d'AOC, des éléments objectifs importants pour réfléchir à l'évolution de leur cahier des charges en matière de conditions de production du lait. Ils renvoient aux mesures à mettre en œuvre pour faire évoluer ou maintenir certaines caracté- ristiques spécifiques des animaux (par exemple le variant $C$ de la caséine $\beta$ en race Tarentaise pour la production de Beaufort) ou de leur alimentation (maintien de la biodivesité des prairies) afin que le fromage reflète au mieux l'originalité et la diversité du territoire où il est produit.

\section{Références}

Agabriel C., Coulon J.B., Journal C., Sibra C., Albouy H., 1999. Variabilité des caractéristiques des fromages Saint-Nectaire fermiers : relations avec la composition du lait et les conditions de production. Lait, 79, 291-302.

Agabriel C., Martin B., Sibra C., Bonnefoy J.C., Montel M.C., Didienne R., Hulin S., 2004. Effect of production systems on the sensory characteristics of cantal cheeses: a plant-scale study. Anim. Res., 53, 221-234.

Andrews A.T., 1983. Breakdown of caseins by proteinases in bovine milks with high somatic cell counts arising from mastitis or infusion with bacterial endotoxin. J. Dairy Res., 50, 57-66.

Anonymous, 1976. Flavour in goats' milk products. Meieriposten, 65, 849-850.

Auldist M.J., Coats S., Sutherland B.J., Mayes J.J., McDowell G.H., Rogers G., 1996. Effects of somatic cell count and stage of lactation on raw milk composition and the yield and quality of Cheddar cheese. J. Dairy Res., 63, 269-280.

Auldist M.J., Mullins C., O’Brien B., O'Kennedy B.T., Guinee T., 2002. Effect of cow breed on milk coagulation properties. Michwissenschaft, 57, 140-143.

Bakke H., Steine T., Eggum A., 1976. Relationship between content of free fatty acids and flavour in goat's milk. Meieriposten, 65, 187-194.

Bakke H., Steine T., Eggum A., 1977. Flavour score and content of free fatty acids in goat milk. Acta Agric. Scand., 27, 245-249.

Bakkene G., 1985. Effect of crossbreeding on quality of goat's milk. Meieriposten, 7, 35-39.

Barbano D.M., Rasmussen R.R., Lynch J.M., Lynch M., 1991. Influence of somatic cell count and milk age on cheese yield. J. Dairy Sci., 74, 369-388.

Benslimane S., Dognin-Bergeret M.J., Berdagué J.L., Gaudemer Y., 1990. Variation with season and lactation of plasmin and plasminogen concentrations in Montbéliard cows'milk. J. Dairy Res., 57, 423-435.

Bérodier F., 1997. Crus de Comté, flore des prairies et pratiques agricoles. Du terroir au goût des fromages. $5^{\text {th }}$ plenary meeting AIR 2039 COST'95, 27-28 Septembre 1997, Besançon France, 186-189.

Bosset J.O., Bütikofer U., Gauch R., Sieber R., 1994. Caractérisation de fromages d'alpages subalpins suisses : mise en évidence par GC-MS de terpènes et d'hydrocarbures aliphatiques lors de l'analyse par « Purge and Trap » des arômes volatils de ces fromages. Schweiz. Milchw. Forschung., 23, 37-41.

Bosset J.O., Jeangros B., Berger T., Bütikofer U., Collomb M., Gauch R., Lavanchy P., Scehovic J., Sieber R., 1999. Comparaison de fromages à pâte dure de type gruyère produits en région de montagne et de plaine. Rev. Suisse Agric., 31, 17-22.

Boulanger A., Grosclaude F., Mahé M.F., 1984. Polymorphisme des casénes $\alpha_{\mathrm{s} 1}$ et $\alpha_{\mathrm{s} 2}$ de la chèvre (Capra hircus). Génét. Sél. Evol., 16 , 157-176.

Buchin S., Delague V., Duboz G., Berdagué J.L., Beuvier E., Pochet S., Grappin R., 1998. Influence of pasteurization and fat composition of milk on the volatile compounds and flavor characteristics of a semi-hard cheese. J. Dairy Sci., 81, 3097-3108

Buchin S., Martin B., Dupont D., Bornard A., Achilleos C., 1999. Influence of the composition of Alpine highland pasture on the chemical, rheological and sensory properties of cheese. J. Dairy Res., 66, 579-588.

Bugaud C., Buchin S., Noël Y., Tessier L., Pochet S., Martin B., Chamba J.F., 2001. Relationships between Abondance cheese texture, its composition and that of milk produced by cows grazing different types of pastures. Lait, $81,593-607$

Bugaud C., Buchin S., Hauwuy A., Coulon J.B., 2002. Texture et flaveur du fromage selon la nature du pâturage : cas du fromage d'Abondance. INRA Prod. Anim., 15, 31-36.

Carpino S., Horne J., Melilli C., Licitra G., Barbano D.M. VanSoest P.J., 2004a. Contribution of native pasture to the sensory properties of Ragusano cheese. J. Dairy Sci., 87, 308-315

Carpino S., Mallia S., LaTerra S., Melilli C., Licitra G., Acree T.E., Barbano D.M., VanSoest J.V., 2004b. Composition and aroma compounds of Ragusano cheese: Native pasture and total mixed rations. J. Dairy Sci., 87, 816-830.

Cavani C., Bianconi L., Manfredini M., Rizzi L., Zarri M.C., 1991. Effects of a complete diet on the qualitative characteristics of ewe milk and cheese. Small Ruminant Res., 5, 273-284.

Chazal M.P., Chilliard Y., 1986. Effect of stage of lactation, stage of pregnancy, milk yield and herd management on seasonal variation in spontganeous lipolysis in bovine milk. J. Dairy Res., 53, 529-538.

Chianese L., Garro G., Mauriello R., Laezza P., Ferranti P.N., Addeo F., 1996. Occurrence of five $\alpha_{\mathrm{s1}}$-casein variants in ovine milk. J. Dairy Res., 63, 49-59.

Chilliard Y., Ferlay A., Doreau M., 2001. Effect of different types of forages, animal fat or marine oils in cow's diet on milk fat secretion and composition, especially conjugated linoleic acid (CLA) and polyinsaturated fatty acids. Livest. Prod. Sci., 70, 31-48.

Chilliard Y., Ferlay A., Mansbridge R.M., Doreau M., 2000. Ruminant milk fat plasticity: nutritional control of saturated, polyunsaturated, trans aconjugated fatty acids. Ann. Zootech., 49, 151-205.

Chilliard Y., Ferlay A., Rouel J., Lamberet G. 2003. A review of nutritional and physiological factors affecting goat milk lipid synthesis and lipolysis. J. Dairy Sci., 86, 1751-1770.

Collomb M., Bütikofer U., Spahni M., Jeangros B., Bosset J.O., 1999. Composition en acides gras et en glycérides de la matière grasse du lait de vache en zone de montagne et de plaine. Sci. Aliments, 19, 97-110.

Cooney S., Tiernan D., Joyce P., Kelly A. 2000. Effect of somatic cell count and polymorphonuclear leucocyte content of milk on composition and proteolysis during ripening of Swiss-type cheese. J. Dairy Res., 67, 301-307.

Cornu A., Carnat A.P., Martin B., Coulon J.B., Lamaison J.L., Berdague J.L., 2001. Solid phase microextraction of volatile components from natural grassland plants. J. Agric. Food Chem., 49, 203-209.

Coulon J.B., Chilliard Y., Rémond B., 1991. Effets du stade physiologique et de la saison sur la composition chimique du lait de vache et ses caractéristiques technologiques (aptitude à la coagulation, lipolyse). INRA Prod. Anim., 4, 219-228.

Coulon J.B., Verdier I., Pradel P., Almena M., 1998. Effect of lactation stage on the cheesemaking properties of milk and the quality of SaintNectaire-type cheese. J. Dairy Res., 65, 295-305.

Coulon J.B., Priolo A., 2002. Influence of forage feeding on the composition and organolpetic properties of meat and dairy products bases for a " terroir » effect. In: « Multi-fonction grasslands : quality forages, animal products and landscapes ", J.L. Durand, J.C. Emile, C. Huyghe and G. Lemaire (ed.), British Grassland Society, 513-524.

Coulon J.B., Gasqui P., Barnouin J., Ollier A., Pradel P., Pomiès D., 2002. Effect of mastitis type and germ on milk yield and composition during naturally-occuring udder infections in dairy cows. Anim. Res., 51, 383-393. 
Coulon J.B., Rémond B., 1991.Variations in milk output and milk protein content in response to the level of energy supply in the dairy cow : a review. Livest. Prod. Sci., 29, 31-47.

Delacroix-Buchet A., Degas C., Lamberet G., Vassal L., 1996. Influence des variants AA et FF de la caséine $\alpha_{\mathrm{s} 1}$ caprine sur le rendement fromager et les caractéristiques sensorielles des fromages. Lait, 76, 217-241.

Delacroix-Buchet A., Lamberet G., 2000a. Intensity of the spontaneous lipolysis in goat milks and perception of the " goaty " aroma in cheeses. Proc. 7th Int. Conf. Goats, Satellite Symposium, Poitiers, France, 1019-1020.

Delacroix-Buchet A., Lamberet G., 2000 b. Sensorial properties and typicity of goat dairy products. Proc. 7th Int. Conf. Goats, Tours, France, 559-563

Delacroix-Buchet A., Lefier D., Nuyts-Petit V., 1993. Polymorphisme de la caséine $\kappa$ de trois races bovines françaises et aptitude à la coagulation. Lait, 73, 61-72.

Delacroix-Buchet A., Marie C., 1994 Comparaison des variants $\mathrm{A}$ et $\mathrm{C}$ de la caséine $\beta$ des laits de vaches Tarentaises en modèle fromager de type beaufort. 1- Aptitudes fromagères et rendements en frais. Lait, 74, 343-360.

Demarigny Y., Beuvier E., Buchin S., Pochet S., Grappin R., 1997. Influence of raw milk mcroflora on the characteristics of Swiss-type cheeses : II. Biochemical and sensory characteristics. Lait, 77, 151-167.

Demarquilly C., 1998. Ensilage et contamination du lait par les spores butyriques. INRA Prod. Anim., 11, 359-354.

Desmasures N., Gueguen M., 1997. Monitoring the microbiology of high quality milk monthly sampling over 2 years. J. Dairy Res., 64, 271-280.

Ducy M., 1997. Influence du polymorphisme des protéines en fabrication de Pont-l'Evêque. Mémoire de DEA, INAPG, 84 pp.

Dumont J.P., Adda J., 1978. Occurrence of sesquiterpenes in mountain cheeses volatiles. J. Agric. Food Chem., 26, 364-367.

Dupont D., Rémond B., Collin J.C., 1998. ELISA determination of plasmin and plasminogen in milk of individual cows managed without the dry period. Milchwissenschaft, 53, 66-69.

Duthoit F., 2003. Structure des communautés microbiennes du fromage d'AOC Salers par approche moléculaire : lien avec les caractéristiques sensorielles des fromages. Thèse, Université de Clermont-Ferrand I, France, 112 p.

Forss D.A., 1992. Effects of feed on flavour of dairy products. In: Milkfat flavour forum, NZDRI, Palmerston, 4-16.

Froc J., Gilibert J., Daliphar T., Durand P., 1988. Composition et qualité technologique des laits de vaches Normandes et Pie-Noires. 1. Effet de la race. INRA Prod. Anim., 1, 171-177.

Gaborit P., Raynal-Ljutivac K., Laurent A., Chabosseau J.M., Rouel J., Chilliard Y., 2002. Flavour of goat milk and cheeses according to feeding : alfalfa hay or maize silage with oleic sunflower or linseed oil supplementation. In: Multi-fonction grasslands : quality forages, animal products and landscapes, J.L. Durand, J.C.
Emile, C. Huyghe and G. Lemaire eds, British Grassland Society, 562-563.

Galina M.A., Morales R., Lopez B., Carmona M.A., 1996. Effect of somatic cell count on lactation and soft cheese yield by dairy goats. Small Rum. Res., 21, 251-257.

Garel J.P., Coulon J.B., 1990. Effet de l'alimentation et de la race des vaches sur les fabrications de fromage d'Auvergne de SaintNectaire. INRA Prod. Anim., 3, 127-136.

Gonzalez Viñas M.A., Esteban E.M., Cabezas L., 1999. Physico-chemical and sensory properties of Spanish ewe milk cheeses, and consumer preferences. Milchwissenschaft, 54, 326-329.

Grandison A.S., Ford G.D., Millard D., Owen A.J, 1984. Chemical composition and coagulating properties of renneted milks from cows during early lactation. J. Dairy Res., 51, 407416 .

Grandison A.S., Ford G.D., 1986. Effects of variation in somatic cell count on the rennet coagulation properties of milk and on the yield, composition and quality of Cheddar cheese. J. Dairy Res., 53, 645-655.

Grappin R., Coulon J.B., 1996. Terroir, lait et fromage : élements de réflexion. Renc. Rech. Rum., 3, 21-28.

Grosclaude F., Mahé M.F., Brignon G., Di Stagio L., Jeunet R.A., 1987. Mendelian polymorphism underlying quantitative variations of goat $\alpha_{\mathrm{s} 1}$-casein. Génét. Sél. Evol., 19, 399-412.

Grosclaude F., 1988. Le polymorphisme génétique des principales lactoprotéines bovines. Relation avec la qualité, la composition et les aptitudes fromagères du lait. INRA Prod. Anim. $1,5-17$.

Grosclaude F., Martin P., 1997. Casein polymorphisms in the goat. Milk protein polymorphism. Proc. IDF seminar, Palmerston North, New Zealand, Feb. 1997. IDF Brussels, Belgium, 241-253.

Grosclaude F., Ricordeau G., Martin P. Remeuf F., Vassal L., Bouillon J., 1994. Du gène au fromage : le polymorphisme de la caséine $\alpha_{\mathrm{s} 1}$ caprine, ses effets, son évolution. INRA Prod. Anim., 7, 3-19.

Ha J.K., Lindsay R.C., 1991a. Volatile branched-chain fatty acids and phenolic compounds in aged Italian cheese flavors. J. Food Sci., 56, 1241-1250.

Ha J.K., Lindsay R.C., 1991b. Contribution of cow, sheep, and goat milks to characterizing branched-chained fatty acid and phenolic flavors in varietal cheeses. J. Dairy Sci., 74, 3267 3274.

Heil F., Dumont J.P., 1993. Caractéristiques organoleptiques de fromages de chèvre fabriqués à partir de laits contenant des variants génétiques différents de la caséine $\alpha_{\mathrm{s} 1}$. Lait, 73, 559-565.

Houssin B., Foret A., Chenais F., 2002. Effect of winter diet (corn vs. Grass silage) of dairy cows on the organoleptic quality of butter and camembert cheese. Grassland Science in Europe, 7, 572-573.

Hurtaud C., Berthelot D., Delaby L., Peyraud J.L., 2004. Winter feeding systems and dairy cows breed have an impact on Camembert and
Pont L'Evèque PDO cheeses in Normandy. Grassland Science in Europe, 8, 1145-1147.

Jaubert G., Bodin J.P., Jaubert A., 1996. Flavour of goat farm bulk milk. Proc. 6th Int. Conf. Goats, Pékin, Chine, 2, 382-383.

Keen A.R., Wilson R.D., 1992. Effect of breed on colour and flavour. In Milkfat flavour forum, NZDRI, Palmerston, 50-54.

Kefford B., Christian M.P., Sutherland B.J. Mayes J.J., Grainger C., 1995. Seasonal influences on Cheddar cheese manufacture : influence of diet quality and stage of lactation. J. Dairy Res., 62, 529-537.

King J.B.W., 1966. The casein of sheeps milk. In: Biochemical polymorphism of animals Paris, INRA, 427-431.

Klei L., Yun J., Sapru A., Lynch J., Barbano D., Sears P., Galton D., 1998. Effects of milk somatic cell count on cottage cheese yield and quality. J. Dairy Sci., 81, 1205-1213.

Korvald T., 1958. Flavour compounds in goat milk and goat cheese. I. Occurrence of flavour in the different fractions of the milk. Meieriposten, $47,175-179 ; 183-187 ; 209-212$.

Lamberet G., Degas C., Delacroix-Buchet A., Vassal L., 1996. Influence des caractères liés aux allèles $\mathrm{A}$ et $\mathrm{F}$ de la caséine $\alpha_{\mathrm{s} 1}$ caprine sur la flaveur chèvre : fabrications fromagères avec échange de protéines et de matières grasses. Lait, $13,349-361$

Le Quéré J.L., Pierre A., Riaublanc A., Demaizières D., 1998. Characterization of aroma compounds in the volatile fraction of soft goat cheese during ripening. Lait, 78, 279-290.

Lucey J., 1996. Cheesemaking from grass based seasonal milk and problems associated with late lactation milk. J. Soc. Dairy Technol., $49,59-64$.

Lucey J.A., Kindstedt P.S., Fox P.F., 1992 Seasonality : its impact on the production of good quality Mozzarella cheese. In: 3rd Cheese Symposium, National Dairy Products Research Centre, Moorepark, 28-29 Octobre 1992. 4149.

Macheboeuf D., Coulon J.B., D'Hour P., 1993. Effect of breed, protein genetic variants and feeding on cows'milk coagulation properties. J. Dairy Res., 60, 43-54.

Mahé M.F., Grosclaude F., 1989. $\alpha_{\mathrm{s} 1}-\mathrm{Cn}^{\mathrm{D}}$, another allele associated with a decreased synthesis rate at the caprine $\alpha_{2}$-casein locus. Génét. Sél. Evol., 21, 127-129.

Malossini F., Bovolenta S., Piras C., Dalla Rosa M., Ventura W., 1996. Effect of diet and breed on milk composition and rennet coagulation properties. Ann. Zootech., 45, 29-40.

Mariaca R.G., Berger T.F.H., Gauch R., Imhof M.I., Jeangros B., Bosset J.O., 1997. Occurrence of volatile mono- and sesquiterpenoids in highland and lowland plant species as possible precursors for flavor compounds in milk and dairy products, J. Agric. Food Chem., $45,4423-4434$.

Marie C., Delacroix-Buchet A., 1994 Comparaison des variants $\mathrm{A}$ et $\mathrm{C}$ de la caséine $\beta$ des laits de vaches Tarentaises en modèle fromager de type Beaufort. 2- Protéolyse et qualité des fromages. Lait, 74, 443-459. 
Martin B., Coulon J.B., 1995. Facteurs de production du lait et caractéristiques des fromages. II. Influence des caractéristiques des laits de troupeaux et des pratiques fromagères sur les caractéristiques du Reblochon de Savoie fermier, Lait, 75, 133-149.

Martin B., Chamba J.F., Coulon J.B., Perreard E., 1997. Effect of milk chemical composition and clotting characteristics on chemical and sensory properties of Reblochon de Savoie cheese. J. Dairy Res., 64, 157-162.

Martin B., 1998. Validation en conditions réelles de l'effet du polymorphisme de la caséine $\beta$ des vaches tarentaises sur les caractéristiques du fromage de Beaufort. C.R. d'études, GIS Alpes du Nord.

Martin B., Buchin S., Hauwuy A., 2001. Effet de la nature botanique des pâturages sur les caractéristiques sensorielles du fromage de Beaufort. In: I formazzi d'alpeggio e loro tracciabilita'. ANFOSC (ed), Bella, 230-237.

Martin B., Buchin S., Hauwuy A., Laurent P., 2003. Effet des systèmes de production sur la qualité sensorielle des fromages. Etude à l'échelle d'une coopérative produisant du Beaufort, Renc. Rech. Rum., 10, 237-238.

Martin B., Pradel P., Verdier-Metz I., 2000. Effet de la race (Holstein/Montbeliarde) sur les caractéristiques chimiques et sensorielles des fromages. Renc. Rech. Rum., 7, 317.

Martin B., Verdier-Metz I., Cornu A., Pradel P., Hulin S., Buchin S., Dupont D., Lamaison J., Carnat A.P., Berdagué J.L, Coulon J.B., 2002. Do terpènes influence the flavour of cheeses ? II Cantal cheese. Caseus Intern. 3, 25-27.

Martin B., Cornu A., Kondjoyan N., Ferlay A., Verduer-Metz I., Pradel P., Rock E., Chilliard Y., Voulon J.B., Berdagué J.L., 2002. Comment reconnaitre la nature des fourrages consommés par les vaches laitières ? Approches analytiques en cours de développement à l'INRA. In: CIDIL (Ed) CDR, $26^{\text {th }}$ IDF World Dairy Congress Congrilait, Paris, 2002

Michalski M.C., Gassi J.Y., Famelart M.H., Leconte N., Camier B., Michel F., Briard V., 2003 The size of native milk fat globules affects physico-chemical and sensory properties of Camembert cheese. Lait, 83, 131-143.

Michel V., Hauwuy A., Chamba J.F., 2001. La flore microbienne de laits crus de vache : diversité et influence des conditions de production. Lait, 81, 575-592.

Mistry V.V., Brouk M.J., Kasperson K.M., Martin E., 2002. Cheddar cheese from milk of Holstein and Brown Swiss cows. Milchwissenchaft, 57, 19-23.

Moio L., Rillo L., Ledda A., Addeo F., 1996. Odorous constituents of ovine milk in relationship to diet. J. Dairy Sci., 79, 1322-1331.

Monnet J.C., Bérodier F., Badot P.M., 2000. Characterization and localization of a cheese georegion using edaphic criteria (Jura Mountains, France), J. Dairy Sci., 83, 16921704

Morgan F., Gaspard C.E., 1999. Influence des cellules somatiques sur les qualités technologiques du lait de chèvre et sur les caractéristiques des fromages de chèvre. Renc. Rech. Rum., 6, 317.
Munro G.L., Grieve P.A., Kitchen B.J., 1984. Effects of mastitis on milk yield, milk composition, processing properties and yield and quality of milk products. Aust. J. Dairy Technol., 39, 7-16.

Niki R., Arima S., 1984. Effects of size of casein micelle on firmness of rennet curd. Jpn. J. Zootech. Sci., 55, 409-415.

Nuyts-Petit V., 1991. Influence des variants génétiques des caséines bovines sur l'aptitude fromagère du lait de vaches de races traditionnelles. Thèse, Université de Compiègne, $161 \mathrm{p}$.

Nuyts-Petit V., Delacroix-Buchet A., Vassal L., 1997. Influence de trois haplotypes des caséines $\alpha_{\mathrm{s} 1}, \beta$ et $\kappa$ fréquents en race bovine Normande sur la composition du lait et l'aptitude à la fabrication fromagère. Lait, 77, 625-639.

O’Farrell I.P., Sheehan J.J., Wilkinson M.G., Harrington D., Kelly A.L., 2002. Influence of addition of plasmin or mastitic milk to cheesemilk on quality of smear-ripened cheese. Lait, $82,305-316$

O'Keeffe A.M., 1984. Seasonal and lactational influences on moisture content of Cheddar cheese. Irish J. Food Sci. Technol., 8, 27-37.

Papoff C.M., Delacroix-Buchet A., Le Bars D., Campus R.L., Vodret A., 1995. Hydrolysis of bovine beta-casein $\mathrm{C}$ by plasmin. Italian J. Food Sci., 7, 157-168

Park Y.W., Anderson M.J., Walters J.L., Mahoney A.W., 1983. Effects of processing methods and agronomic variables on carotene contents in forages and predicting carotene in alfalfa hay with near-infrared-reflectance spectroscopy. J. Dairy Sci., 66, 235-245.

Pierre A., Le Quéré J.L., Famelart M.H., Riaublanc A., Rousseau F., 1998. Composition, yield, texture and aroma compounds of goat cheeses as related to the $\mathrm{A}$ and $\mathrm{O}$ variants of $\alpha_{\mathrm{s} 1}$-casein in milk. Lait, 78, 291-301.

Pirisi A., Achilleos C., Jaros D., Noel Y. Rohm H., 2000a. Rheological characterisation of Protected Denomination of Origin-(PDO)-cheeses made from ewe's milk. Milchwissenschaft, $55,257-259$

Pirisi A., Colin O., Laurent F., Scher J., Parmentier M., 1994. Comparison of milk composition, cheesemaking properties and textural characteristics of the cheese from two groups of goats with a high or low rate of $\alpha_{\mathrm{s} 1}$-casein synthesis. Int. Dairy J., 4, 329-345.

Pirisi A., Fraghì A., Piredda G., Leone P., 1999a. Influence of sheep AA, AB and BB $\beta$-lactoglobulin genotypes on milk composition and cheese yield. In: Milking and milk production of dairy sheep and goats. Den Haag, Netherlands, EAAP Publication, 95, 553-555.

Pirisi A., Piredda G., Corona M., Pes M., Pintus S., Ledda A., 2000b. Influence of somatic cell count on ewe's milk composition, cheese yield and cheese quality. Proceedings of 6th Great Lakes Dairy Sheep Symposium, Guelph, Canada, 47-59.

Pirisi A., Piredda G., Fraghì A., Papoff C.M., Chianese L., 1997. Influence of sheep AA, CC and $\mathrm{DD} \alpha_{\mathrm{s} 1}$ casein variants on milk composition and cheese yield. In: Milk protein polymorphism. Brussels, Belgium, Int. Dairy Fed., 9702, 254-258
Pirisi A., Piredda G., Papoff C.M., Di Salvo R., Pintus S., Garro G., Ferranti P., Chianese L. 1999b. Effect of sheep $\alpha_{\mathrm{s} 1}$-casein CC, CD and DD genotypes on milk composition and cheesemaking properties. J. Dairy Res., 66, 409-419.

Pirisi A., Piredda G., Podda F., Pintus S., 1996. Effect of somatic cell count on sheep milk composition and cheesemaking properties. In: Somatic cells and milk of small ruminants. Den Haag, Netherlands, EAAP Publication, 77, 245-251.

Politis I., Ng-Kwai-Hang K.F., 1988a. Effects of somatic cell counts and milk composition on the coagulating properties of milk. J. Dairy Sci., 71, 1740-1746.

Politis I., Ng-Kwai-Hang K.F., 1988b. Effect of somatic cell count and milk composition on cheese composition and cheese making efficiency. J. Dairy Sci., 71, 1711-1719.

Pomiès D., Martin B., Rémond B. Brunschwig G., Pradel P., Lavigne R., Hulin S. 2003. La traite une fois par jour pendant 7 semaines de vaches laitières Prim'Holstein et Montbéliarde en milieu de lactation : performances zootechniques, qualité du lait et des fromages. Renc. Rech. Rum., 10, 81-84.

Prache S., Priolo A., Tournadre H., Jailler R., Dubroeucq H., Micol D., Martin B., 2002. Traceability of grass-feeding by quantifying the signature of carotenoid pigments in herbivores meat, milk and cheese. In: Multi-fonction grasslands : quality forages, animal products and landscapes, J.L. Durand, J.C. Emile, C. Huyghe and G. Lemaire (eds), British Grassland Society, 592-593.

Remeuf F., 1993. Influence du polymorphisme génétique de la caséine $\alpha_{\mathrm{s} 1}$ caprine sur les caractéristiques physico-chimiques et technologiques du lait. Lait, 73, 549-557.

Remeuf F., Cossin V., Dervin C., Lenoir J., Tomassone R., 1991. Relations entre les caractères physico-chimiques des laits et leur aptitude fromagère. Lait, 71, 397-421.

Rémond B., Pomiès D., 2004. Effect of once daily milking in dairy cows : a review of recent french experiment. EAAP, à paraître.

Requena R., Molina F., Fernández N., Ro-dríguez M., Peris C., Torres A.,1999. Changes in milk and cheese composition throughout lactation in Manchega sheep. In: Milking and milk production of dairy sheep and goats. Den Haag, Netherlands, EAAP Publication, 95, 501-506.

Ronningen K., 1965. Causes of variation in the flavor intensity of goat milk. Acta Agric. Scand., 15, 301-343.

Skjevdal T., 1979. Flavour of goat's milk: a review of studies on the sources of its variation. Livest. Prod. Sci., 6, 397-405.

Sutton J.D., 1989. Altering milk composition by feeding. J. Dairy Sci., 72, 2801-2814.

Toso B., Stephanon B., 2001. Effect of ration composition on sensory properties of matured Montasio cheese Scienza e Tecnica Latterio Casearia, 52, 257-268.

Trujillo A.J., Miranda G., Le Bars D., Delacroix-Buchet A., 1997. Proteolytic specificity of chymosin on caprine $\alpha_{\mathrm{s} 1}$-casein A and F. J. Dairy Res., 65, 233-241. 
Tziboula A., Banks J.M., Horne D.S., 1997. Genetic polymorphism in caprine $\alpha_{\mathrm{s} 1}$-casein studies on rennet gelation kinetics and sensory properties of hard cheeses. Milk protein polymorphism : Proc. IDF seminar, Palmerston North, New Zealand, Feb. 1997. IDF Brussels, Belgium, 294-296.

Urbach G., 1997. The flavour of milk and dairy products : II. Cheese: contribution of volatile compounds. Int. J. Dairy Technol.,, 50, 79-89.

Urbach G., 1990. Effect of feed on flavor in dairy foods. J.Dairy Sci., 73, 3639-3650.

Vassal L., Delacroix-Buchet A., Bouillon J., 1994. Influence des variants AA, EE et FF de la caséine $\alpha_{\mathrm{s} 1}$ caprine sur le rendement fromager et les caractéristiques sensorielles de fromages traditionnels : premières observations. Lait, 74, 89-103.

Verdier I., Coulon J.B., Pradel P., Berdagué J.L., 1995. Effect of storage type and cow breed on the characteristics of matured Saint-Nectaire cheeses. Lait, 75, 523-533.

Verdier-Metz I., Coulon J.B., Pradel P., Viallon C., Berdagué J.L., 1998. Effect of forage conservation (hay or silage) and cow breed on the coagulation properties of milks and on the characteristics of ripened cheeses. J. Dairy Res., 65, 9-21.

Verdier-Metz I., Coulon J.B., Viallon C., Pradel P., 2000a. Effet de la conservation du fourrage sur les caractéristiques physicochimiques et sensorielles des fromages. Renc. Rech. Rum., 7, 318.

Verdier-Metz I., Coulon J.B., Pradel P., Viallon C., Albouy H., Berdagué J.L., 2000b. Effect of the botanical composition of hay and casein genetic variants on the chemical and sensory characteristics of ripened Saint-Nectaire type cheese. Lait., 80, 361-370.

Verdier-Metz I., Coulon J.B., Pradel P., 2001. Relationship between milk fat and protein contents and cheese yield. Anim. Res., 50, 365371.

Verdier-Metz I., Pradel P., Coulon J.B., 2002a. Influence of the forage type and conservation on the cheese sensory properties. In: Durand J.L., Emile J.C., Huyghe C., Lemaire G. (eds), Multi-fonction grasslands: quality forages, animal products and landscapes, British Grassland Society, La Rochelle, France, 2002, 592-593.

Verdier-Metz I., Martin B., Hulin S., Ferlay A., Pradel P., Coulon J.B., 2002b. Combined influence of cow diet and pasteurisation of the milk on sensory properties of french PDO cantal cheese. In: CIDIL (ed) CDR, 26 th IDF World Dairy Congress Congrilait, Paris, 2002.

Viallon C., Martin B., Verdier-Metz I., Pradel P., Garel J.P., Coulon J.B. Berdagué J.L., 2000. Transfer of monoterpenes ans sesquiterpenes from forages into milk fat. Lait, 80, 635-641.

Viallon C., Verdier-Metz I., Denoyer C., Pradel P., Coulon J.B., Berdagué J.L., 1999. Desorbed terpenes and sesquiterpènes from forages and cheeses. J. Dairy Res., 66, 319-326.

Waghorn G.C., Khight T.W., 1992. Beta carotène intake, digestion, absorption and metabolism in the dairy cow. In: Milk fat flavour forum: summary of proceedings. New Zeland Research Institute (ed), 42-49.

Woo A.H., Lindsay R.C., 1984 Concentrations of major free fatty acids and flavor development in Italian cheese varieties. J. Dairy Sci., 67,960-968.

Zachos T., Politis I., Gorewit R.C., Barbano D.M., 1992. Effect of mastitis on plasminogen activator activity of milk somatic cells. J. Dairy Res., 59, 461-467.

\section{Résumé}

Cette revue fait le point sur les connaissances acquises au cours des 10 dernières années sur les relations entre les facteurs de conduite des animaux (génétiques, physiologiques, alimentaires) et la qualité sensorielle des fromages. Chez la vache, avec des fabrications au lait entier, la race peut modifier les caractéristiques de texture des fromages. Cet effet est essentiellement lié aux différences de composition chimique des laits et donc de gras/sec des fromages. Au sein d'une même race, des différences importantes de texture et de goût ont été observées en fonction des variants génétiques de la caséine $\beta$ (espèce bovine) et surtout $\alpha_{s 1}$ (espèce caprine). Le stade physiologique n'a un effet marqué sur la couleur, la texture et le goût qu'en tout début ou en toute fin de lactation. En revanche, les mammites ont un effet négatif important sur les caractéristiques sensorielles des fromages. L'utilisation d'ensilage de maïs conduit toujours à des fromages plus blancs et parfois à des différences de flaveur. Lorsqu'elle est correctement réalisée, la conservation de l'herbe sous forme d'ensilage comparativement au foin ne modifie pas ou peu les caractéristiques sensorielles des fromages, en dehors de leur couleur, plus jaune avec l'ensilage. Par contre, d'importantes différences de caractéristiques sensorielles sont observées entre des fromages selon que le lait provient de vaches recevant une ration à base d'herbe conservée ou conduites au printemps, au pâturage. Plusieurs essais récents ont mis en évidence un effet de la composition botanique des fourrages ingérés par les vaches laitières sur la texture et la flaveur des fromages. Ces différents effets sont dus à la présence dans le lait de molécules ou de structures issues directement de l'alimentation (carotènes, terpènes) ou produites par l'animal (plasmine, acides gras, structure des micelles de la caséine) en raison de ses caractéristiques génétiques ou physiologiques ou sous l'effet d'une alimentation spécifique.

\section{Abstract}

\section{Ruminant management and sensory characteristics of cheeses}

This review summarises the last 10 years of knowledge established on the relationships between management of the animals (genetic, physiology, feeding) and sensory quality of cheese. In the production of full fat raw milk cheese, the cow's breed can modify the texture of cheeses because of differences in fat in dry matter content, due to variations in the fat/protein ratio in milk. Within a same breed, large differences in texture and taste were observed between cheeses issued from milk differing by the genetic variant of $\beta$-casein (in dairy cows) or $\alpha_{\mathrm{s} 1}$-casein (in goats). Except in very early or late lactation, the physiological stage had no significant effect on cheese sensory characteristics. In contrast, mastitis has a well known negative impact on cheese sensory properties. Feeding dairy cows or goats with corn silage by comparison with hay or grass silage lead to whiter cheeses and sometimes to differences in flavour. Conserving grass as silage, by comparison with hay, has no important effect on cheese sensory characteristics, except on colour, being more yellow with grass silage. Conversely, major differences in sensory characteristics were observed between cheeses made with milk produced by cows fed winter diets (based on hay and grass silage) or turned to pasture in the spring. Several recent experiments showed a significant effect of grass' botanical composition on cheese texture and flavour. These effects are due to the presence in milk of specific molecules or structures directly induced by feeding (carotenes, terpenes) or produced by the animals (plasmin, fatty acids, casein micellar structures) according to their genetic or physiological characteristics or under the effect of specific diets.

COULON J.B., DELACROIX-BUCHET A., MARTIN B., PIRISI A. 2005. Facteurs de production et qualité sensorielle des fromages. INRA Prod. Anim. 18, 49-62. 